\title{
Paired response of motor units during voluntary contraction in Parkinsonism
}

\author{
A. DAS GUPTA ${ }^{1}$ \\ From the Neurological Unit of the Department of Medicine, Northern General Hospital, Edinburgh
}

Parkinson (1817) believed that the whole complex of Parkinsonism, including tremor, was due to abnormal function of the upper part of the spinal cord and the medulla oblongata. Though a great deal of clinical, pathological, and experimental work, including surgical operation for the Parkinsonian syndrome, has led us to believe that the site of pathology is much higher, in the basal ganglia, it is interesting to note that recent physiological studies are revealing unsuspected disturbances at the level of the medulla and the cord. The part played by the spinal cord and its connexions is not insignificant (Das Gupta, 1962) and so an important pathological mechanism of Parkinsonism lies much closer anatomically to what Parkinson himself suggested over a century ago.

The importance of this local pathology is once again suggested by an observation which is the subject of this paper. It was made incidentally during a study of the behaviour of single motor units of voluntary muscle during sustained isometric contraction, using a steel needle electrode specially prepared for the discrete recording of single motor units. The technique has been fully described elsewhere (Das Gupta and Simpson, 1962).

Observations were made on 10 patients with paralysis agitans. All had tremor as well as rigidity but records were taken when there was no overt tremor or when tremor was so slight as not to affect the picture.

A prominent feature of the firing pattern of single motor units during sustained voluntary contraction was a tendency for the spike discharges to be grouped in pairs (Fig. 1). The intervals between the two spikes were extremely variable, from $20 \mathrm{msec}$. to over $80 \mathrm{msec}$., but usually between 30 and $60 \mathrm{msec}$. With the very localized pick-up area of the electrodes used, it was easy to recognize individual units by their characteristic shape. This criterion left no room for doubt that both spikes of a pair originated from one unit. When there was overt tremor during an experiment there was always synchronous

'Present address: St. Mary's Hospital, Newport, Isle of Wight
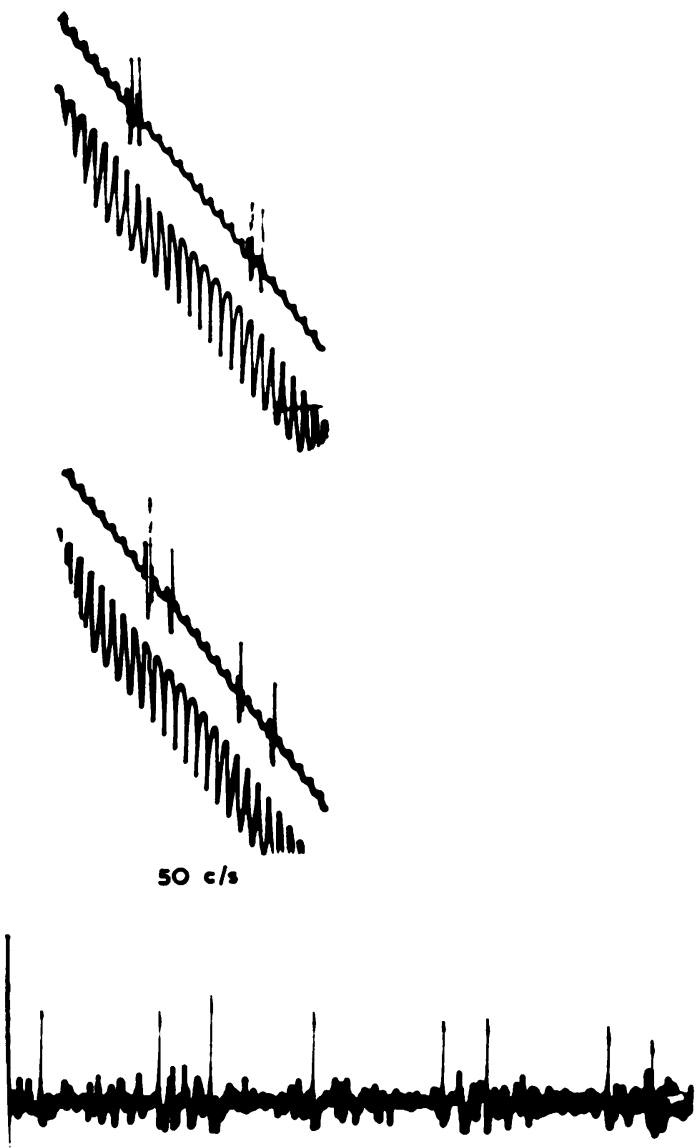

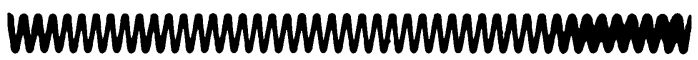
$50 \mathrm{c} / \mathrm{s}$

FIG. 1. Electromyographic appearance of the paired responses. Note the variable intervals between the two components of the paired responses. 

rhythmic series' is accepted there is little doubt that the second component of the paired response arises from the same unit as the first one. There may be slight dissimilarity in the heights of the spikes at times, but 'similar or greater dissimilarity is often seen during repetitive discharge of the same unit during sustained effort' (Gilson and Mills, 1941).

It has been observed by many workers (Adrian and Bronk, 1929; Denny-Brown, 1929; Eccles and Hoff, 1932; Hoff and Grant, 1944) that during firing of a single motor unit it is not uncommon for the motor neurone to give one or two 'double discharges', especially when the neurone is firing at or very near its threshold. Hoff and Grant (1944) put forward the rigid definition that a paired spike can be called a 'double discharge' only when the second beat arises from the same unit as the first one and when the interval between them lies between 2.9 and $20 \mathrm{msec}$. The second spike may be somewhat smaller in amplitude and of greater duration than the first (Gordon and Holbourn, 1949). These double discharges are most commonly seen at the beginning of any contraction, less often at the end (Gilson and Mills, 1941), and this fact led Gordon and Holbourn (1949) to believe that double discharges allow a large initial development of tension which can then be maintained by a fairly low frequency of firing. Kugelberg (1948) observed that double discharges may be somewhat more frequent in the anterior horn cell diseases. He believed that the site of production of these double discharges must be somewhere in the periphery since they can be 'faithfully reproduced' by peripheral electrical stimulation. Denslow (1948) found that a long pause always followed a double discharge and considered that this was a striking feature.

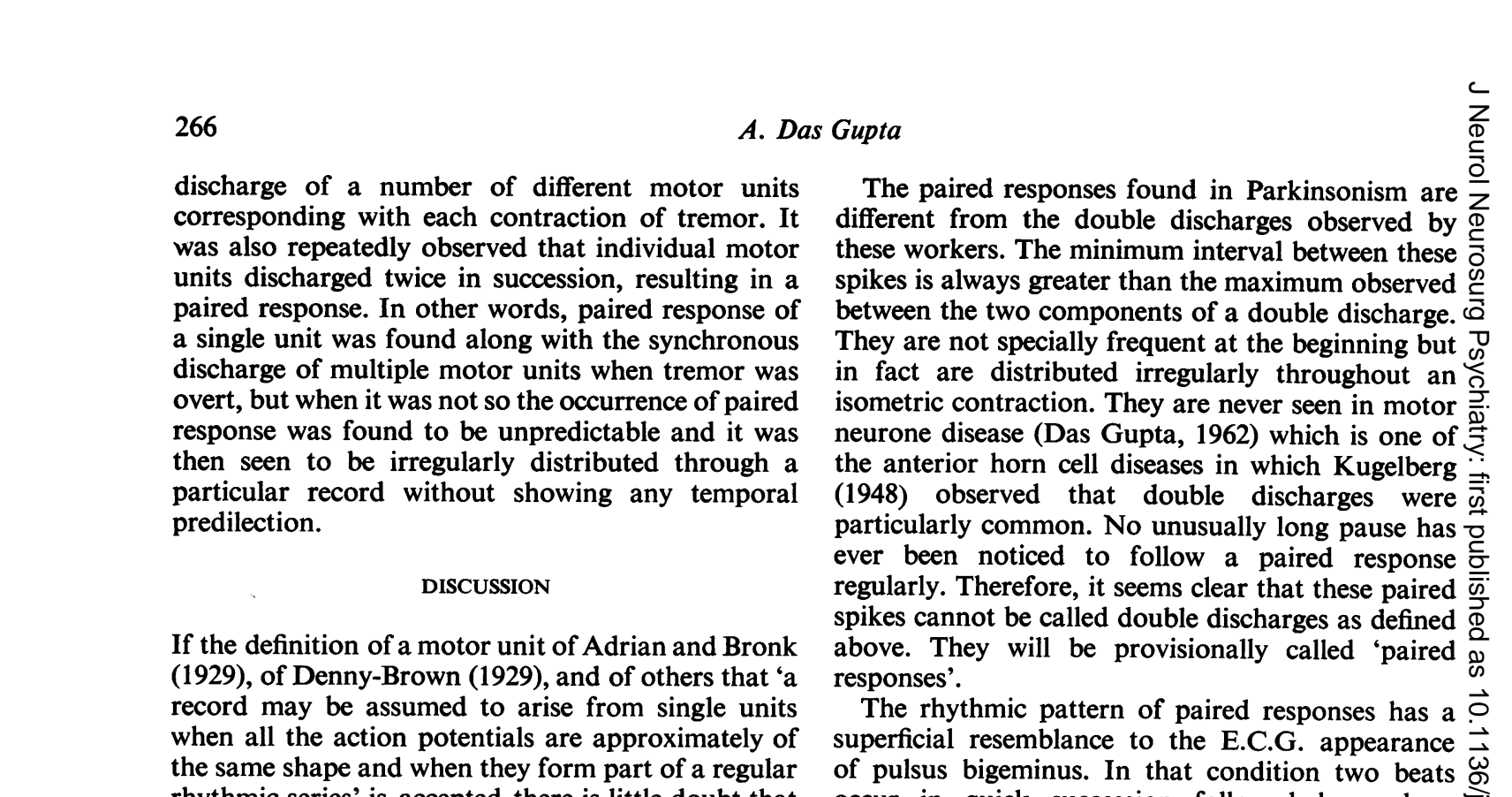

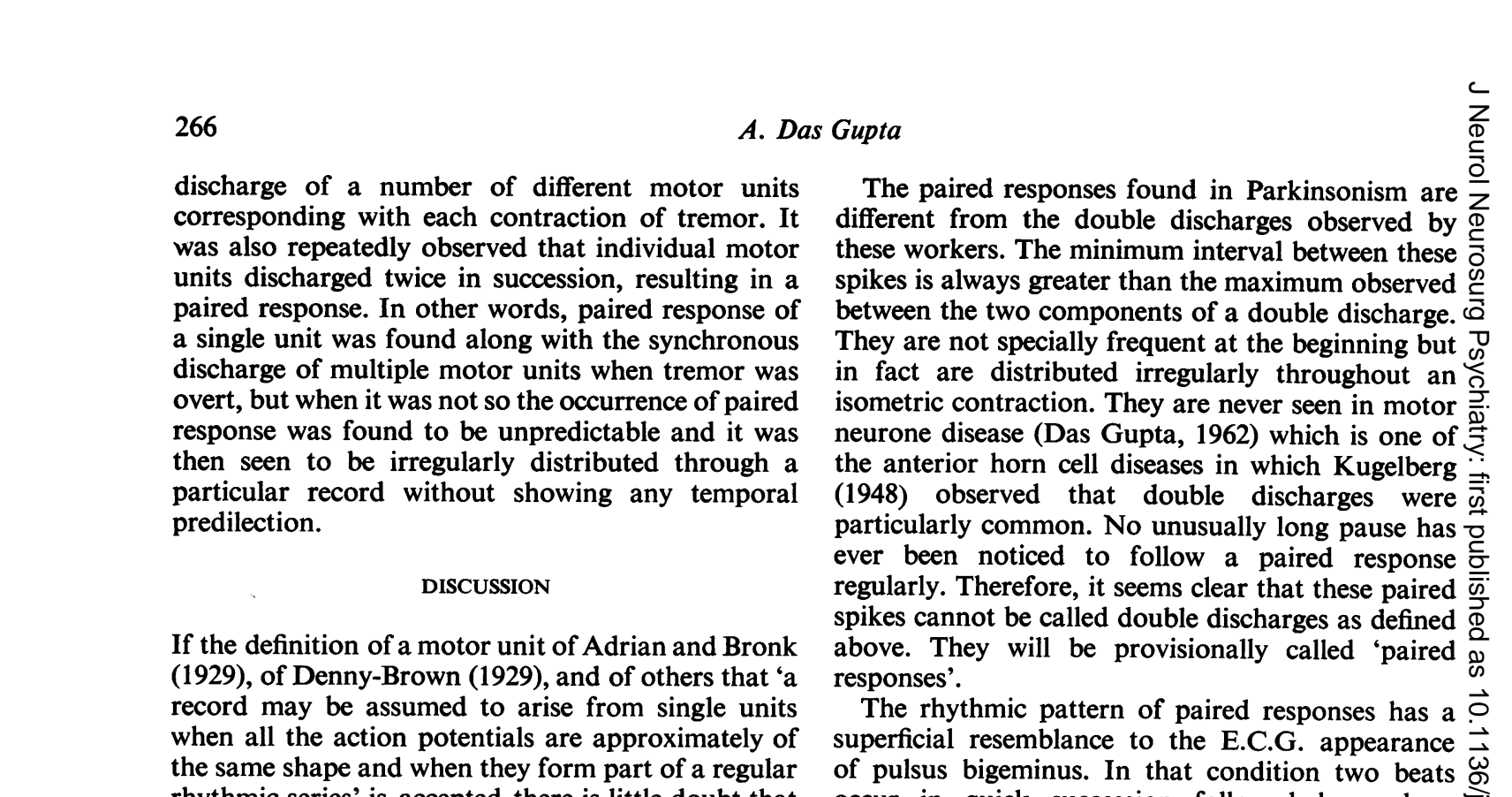

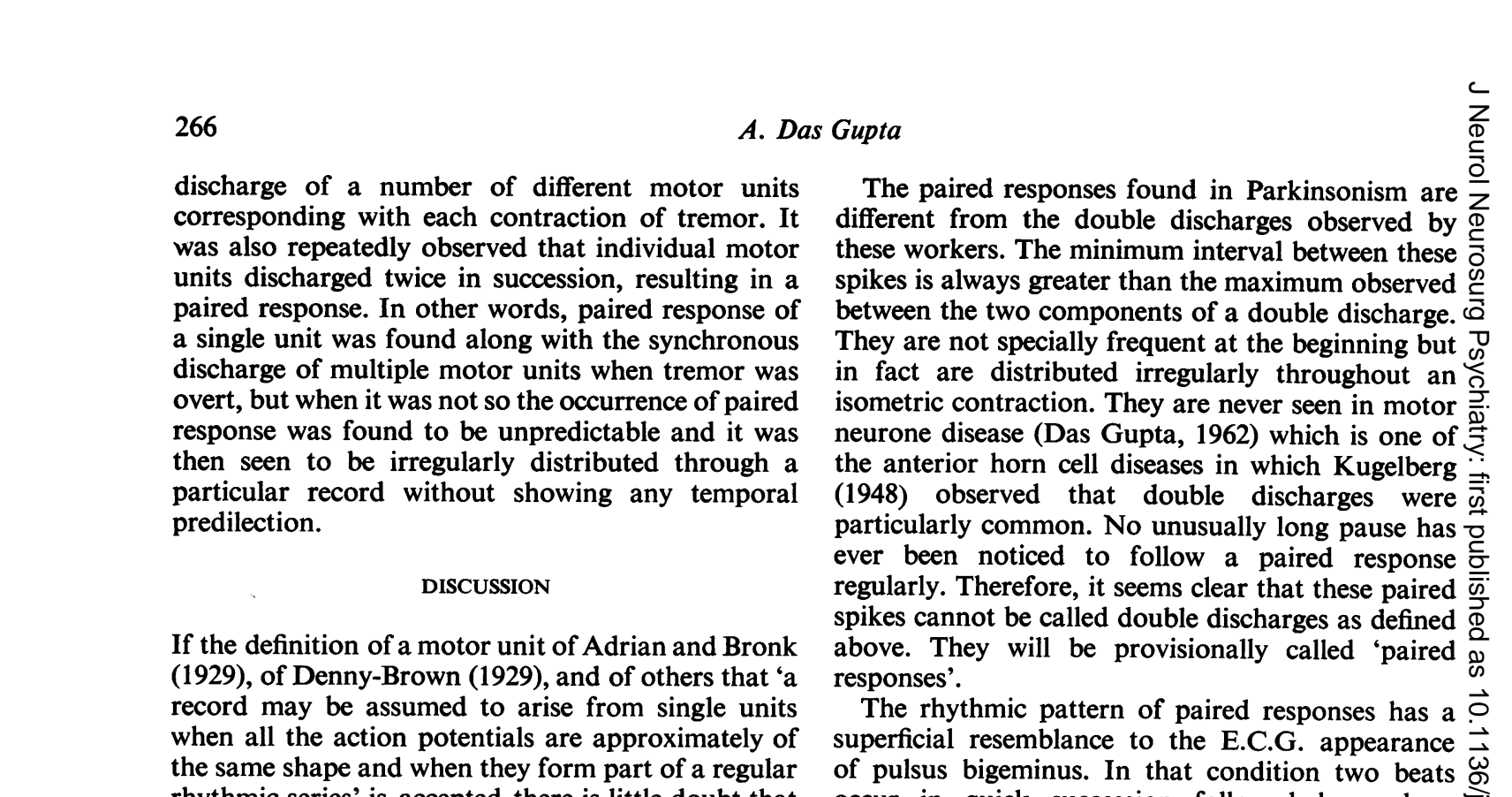

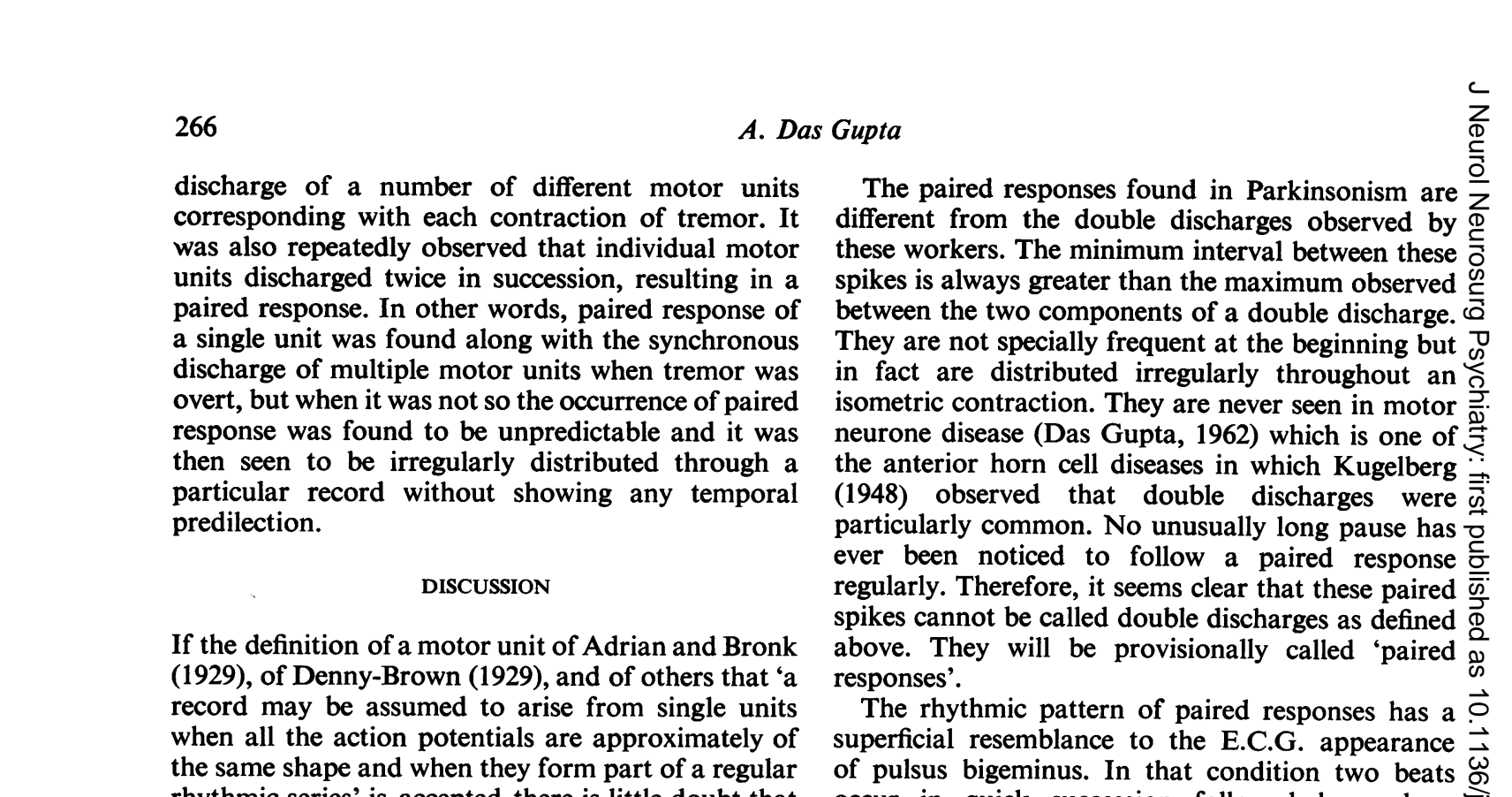

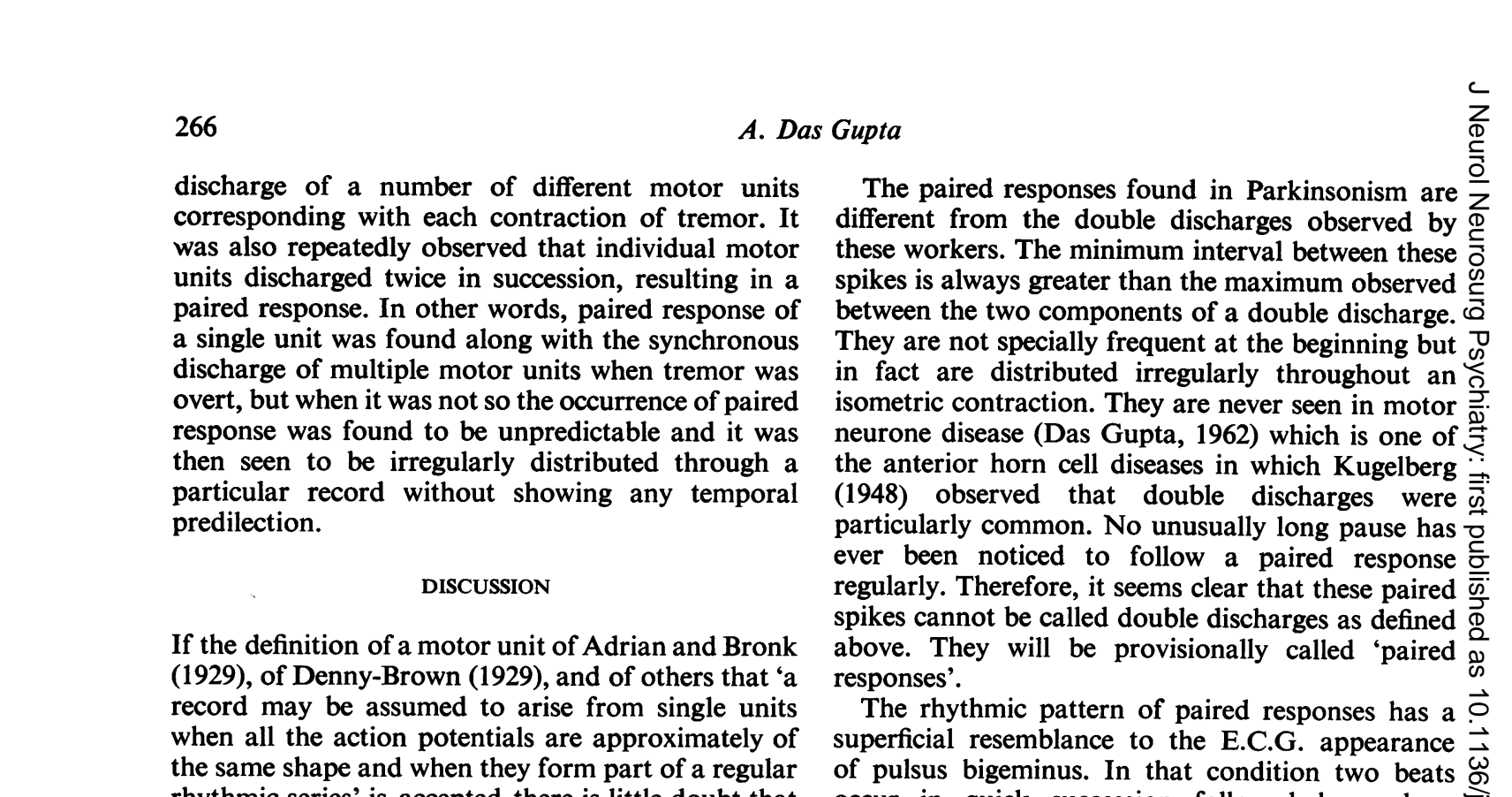

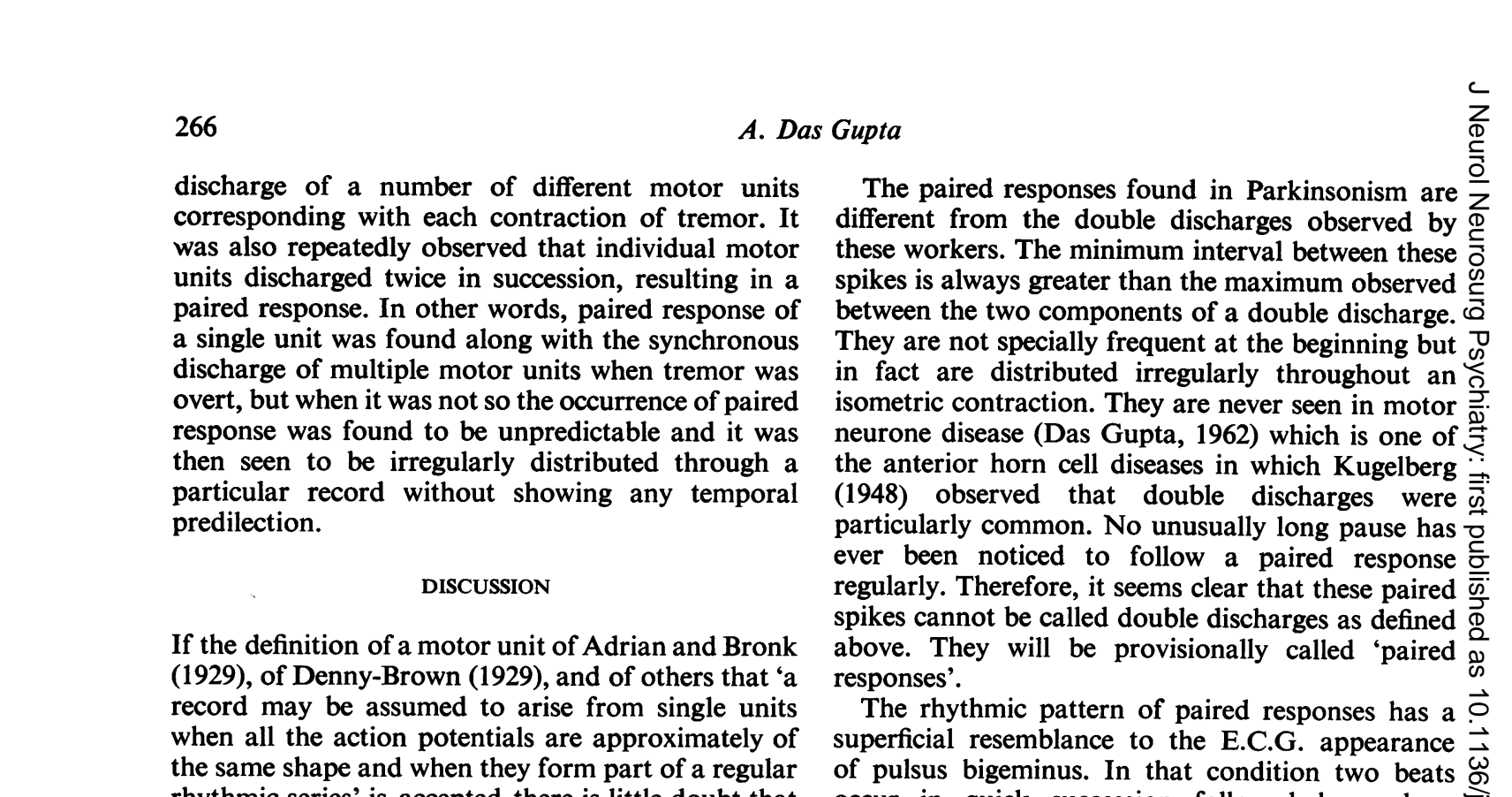

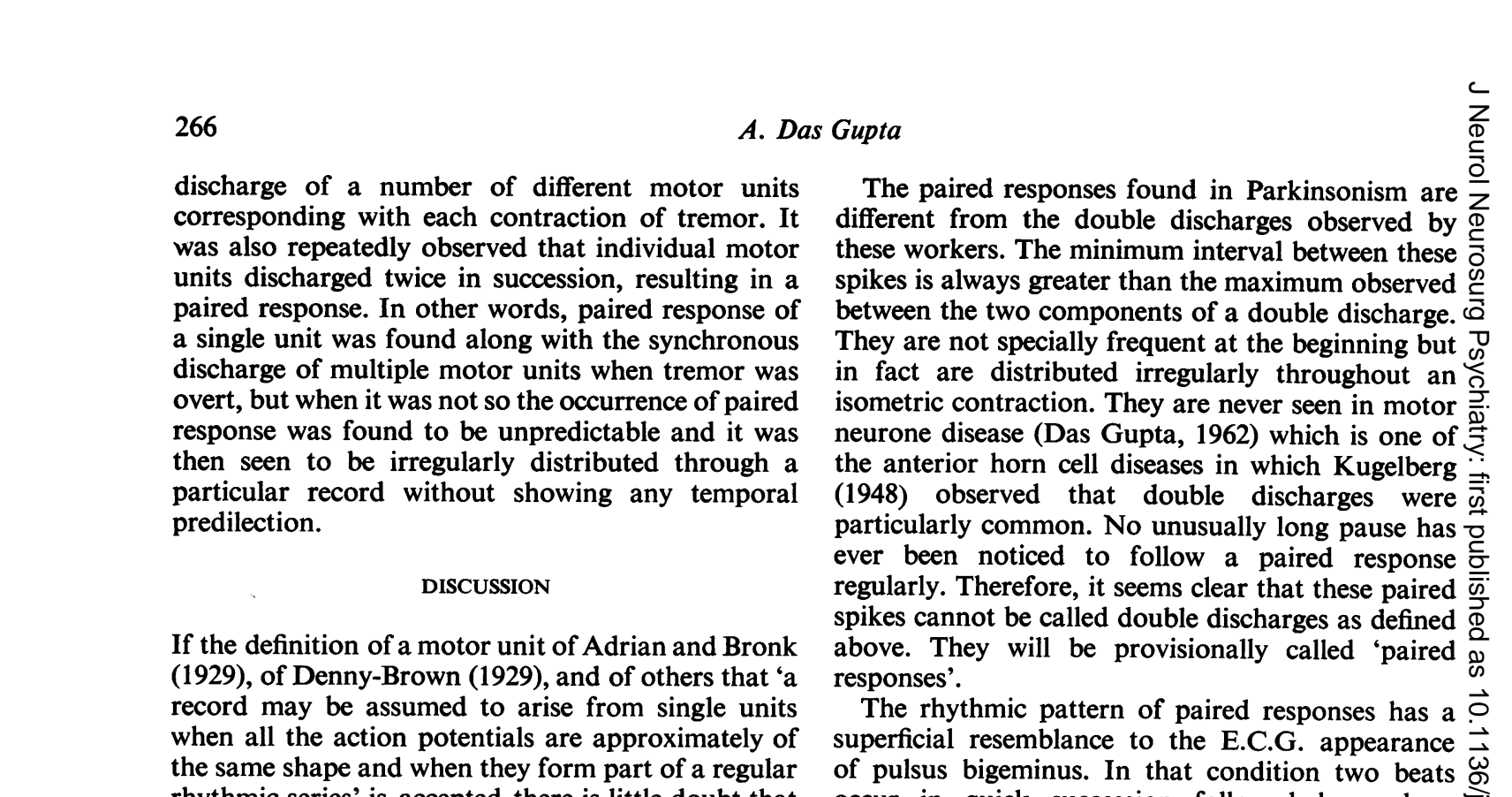

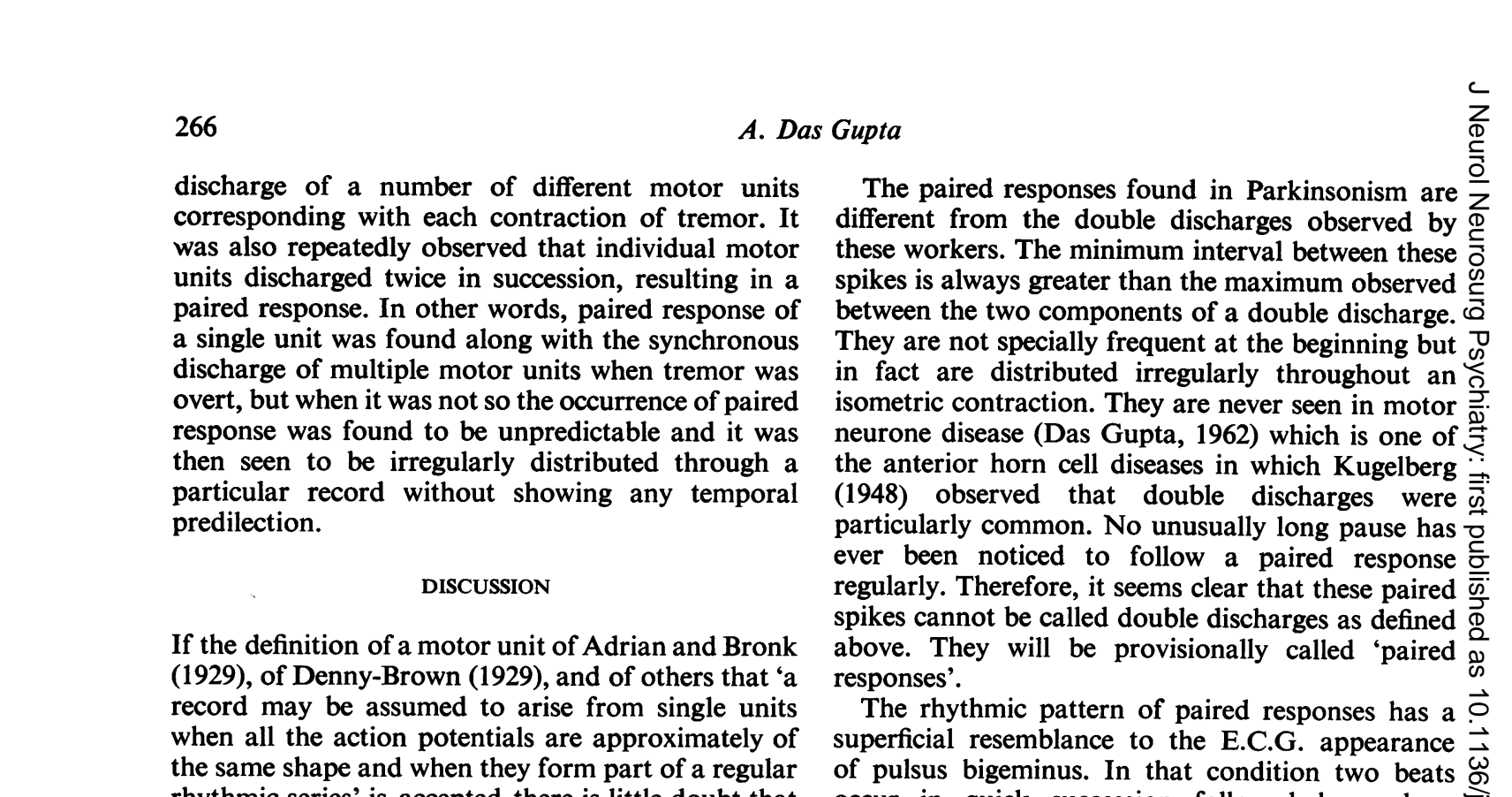

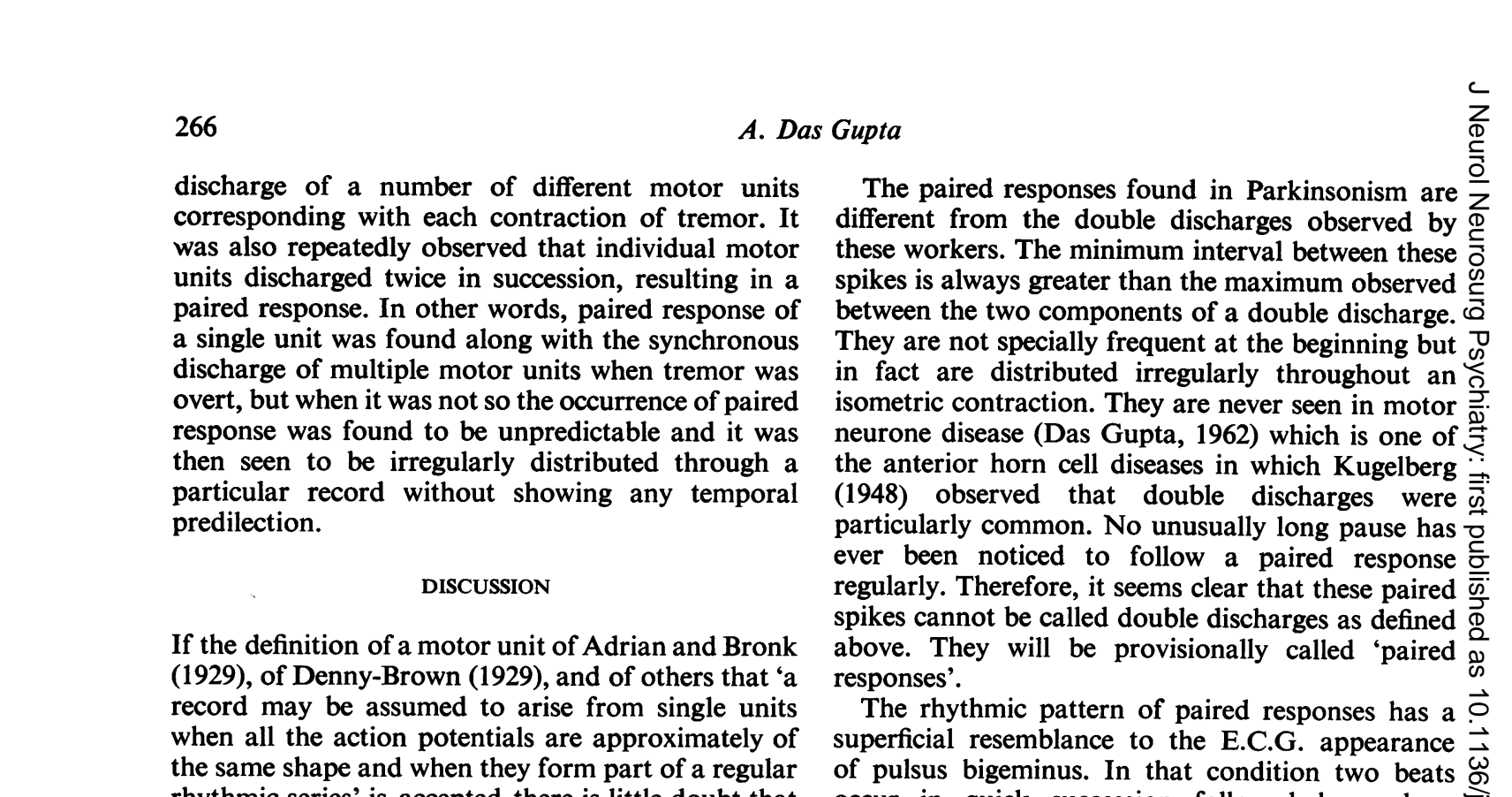

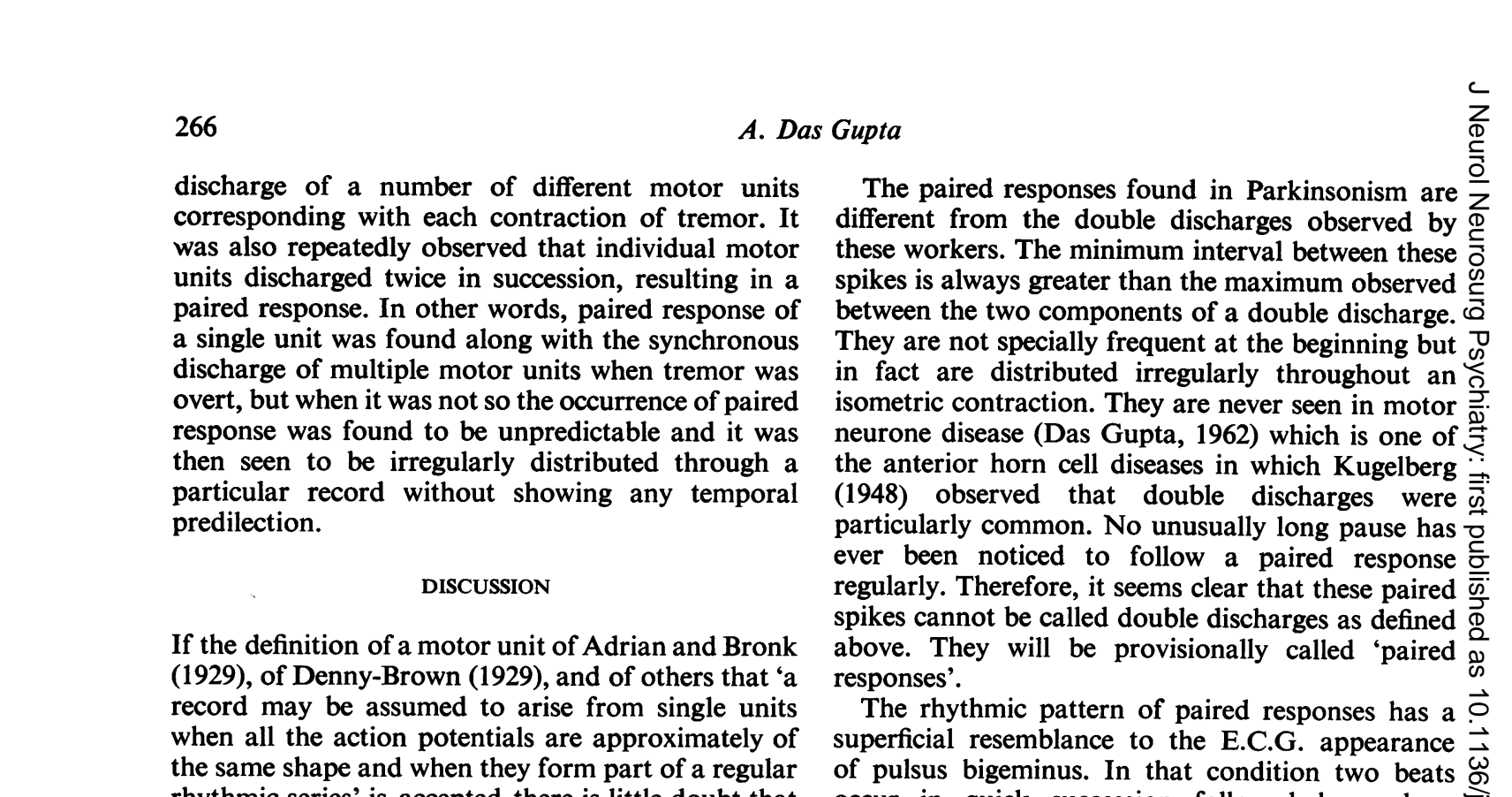

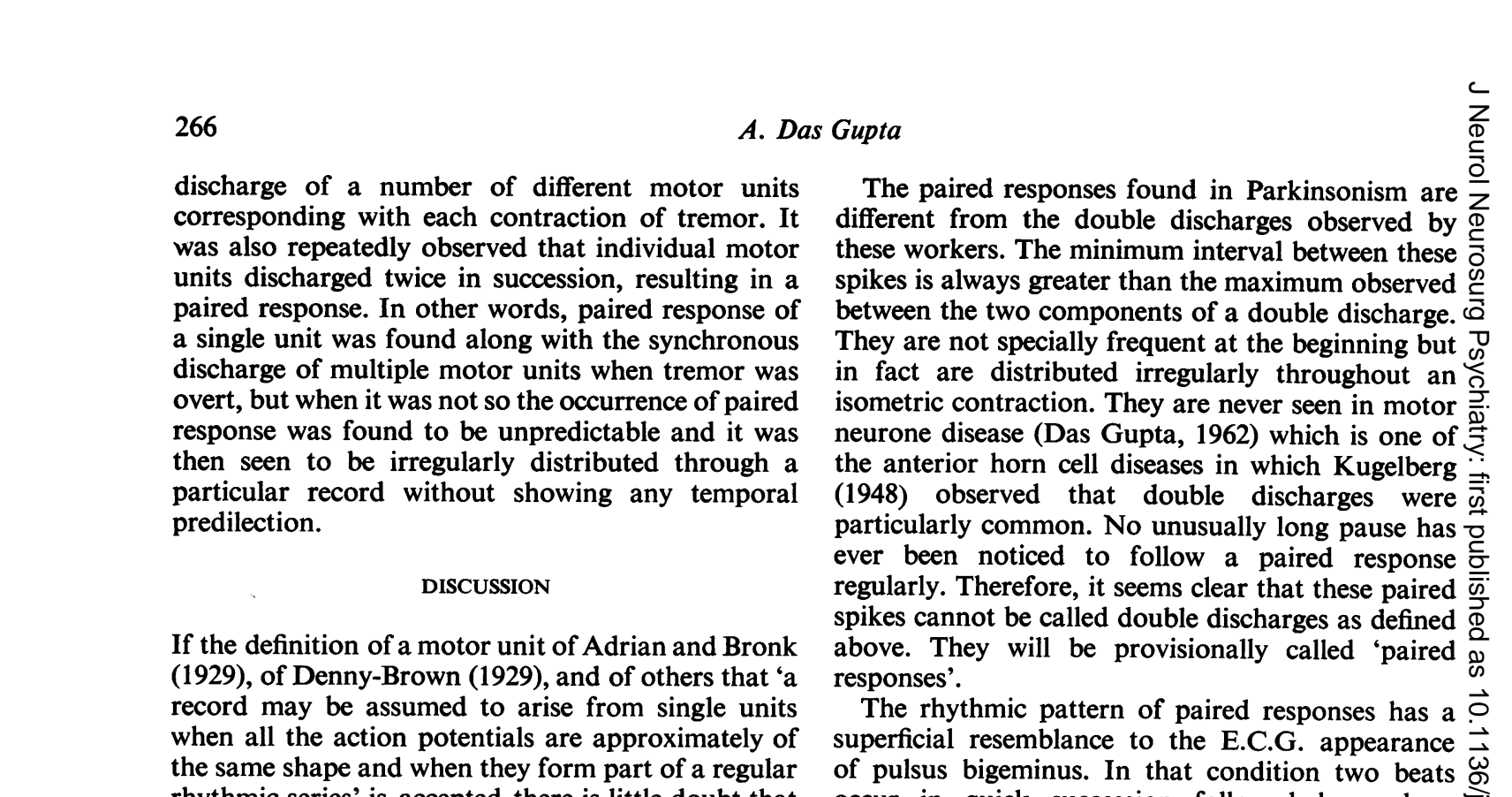

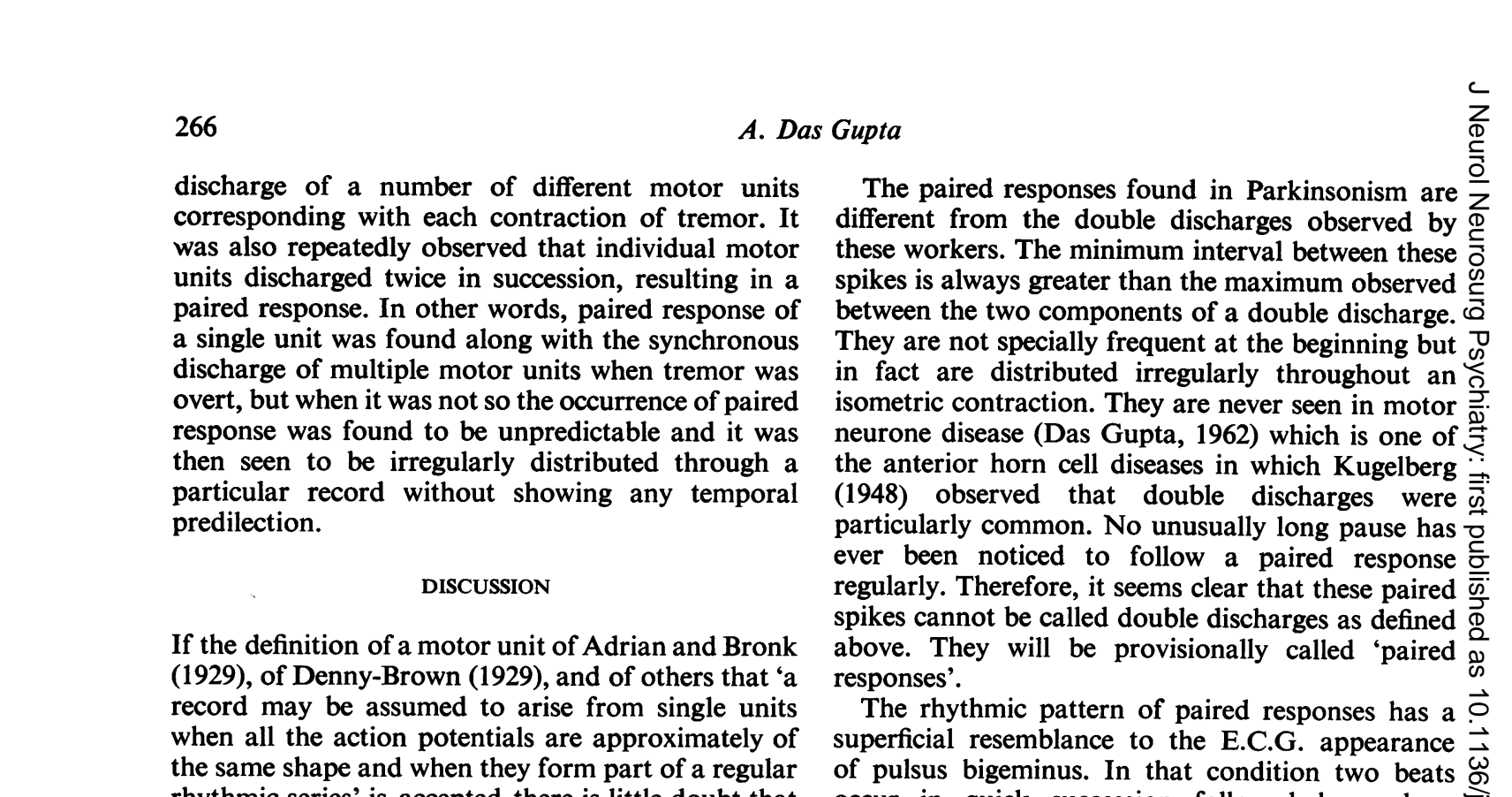

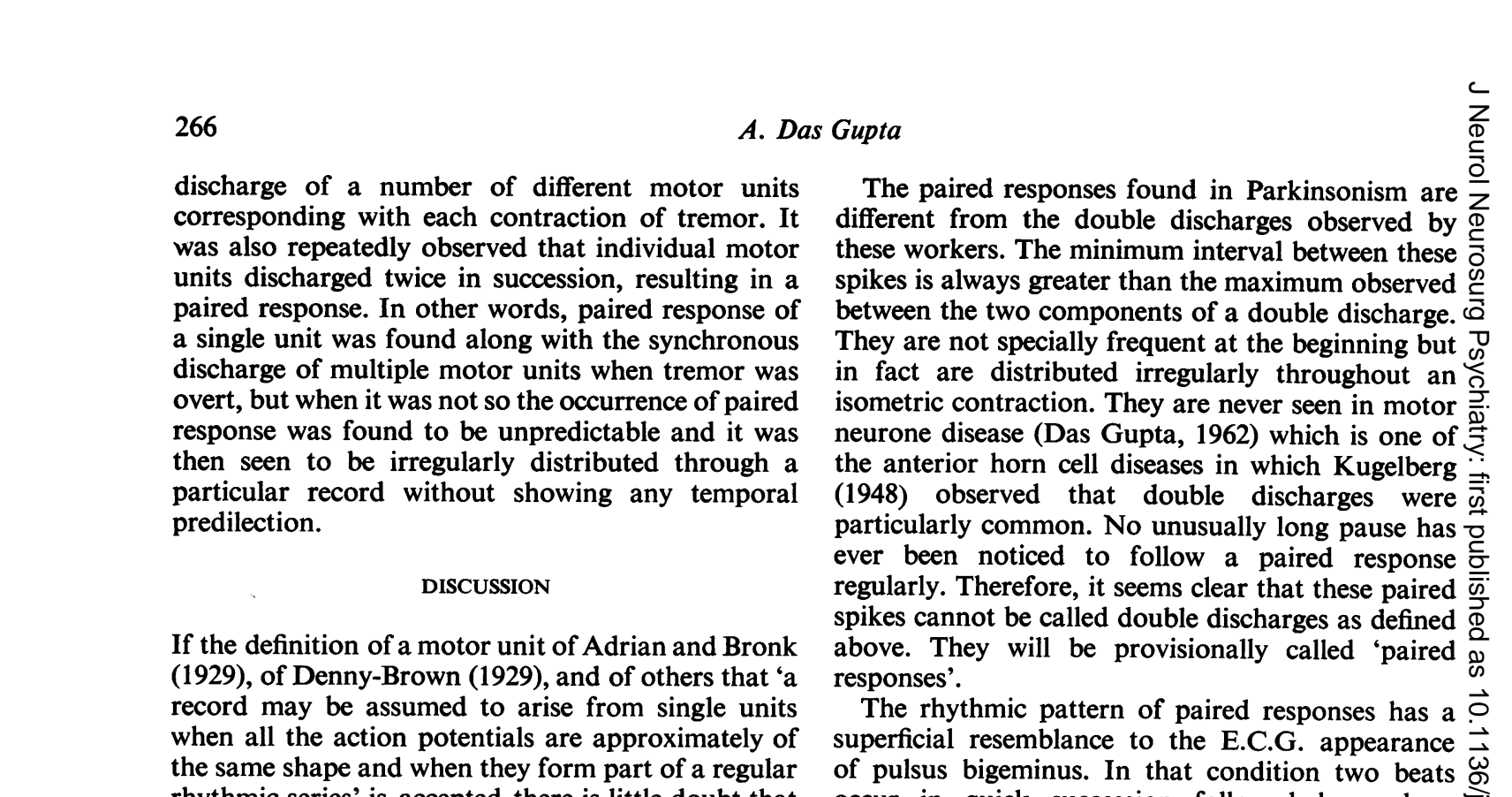

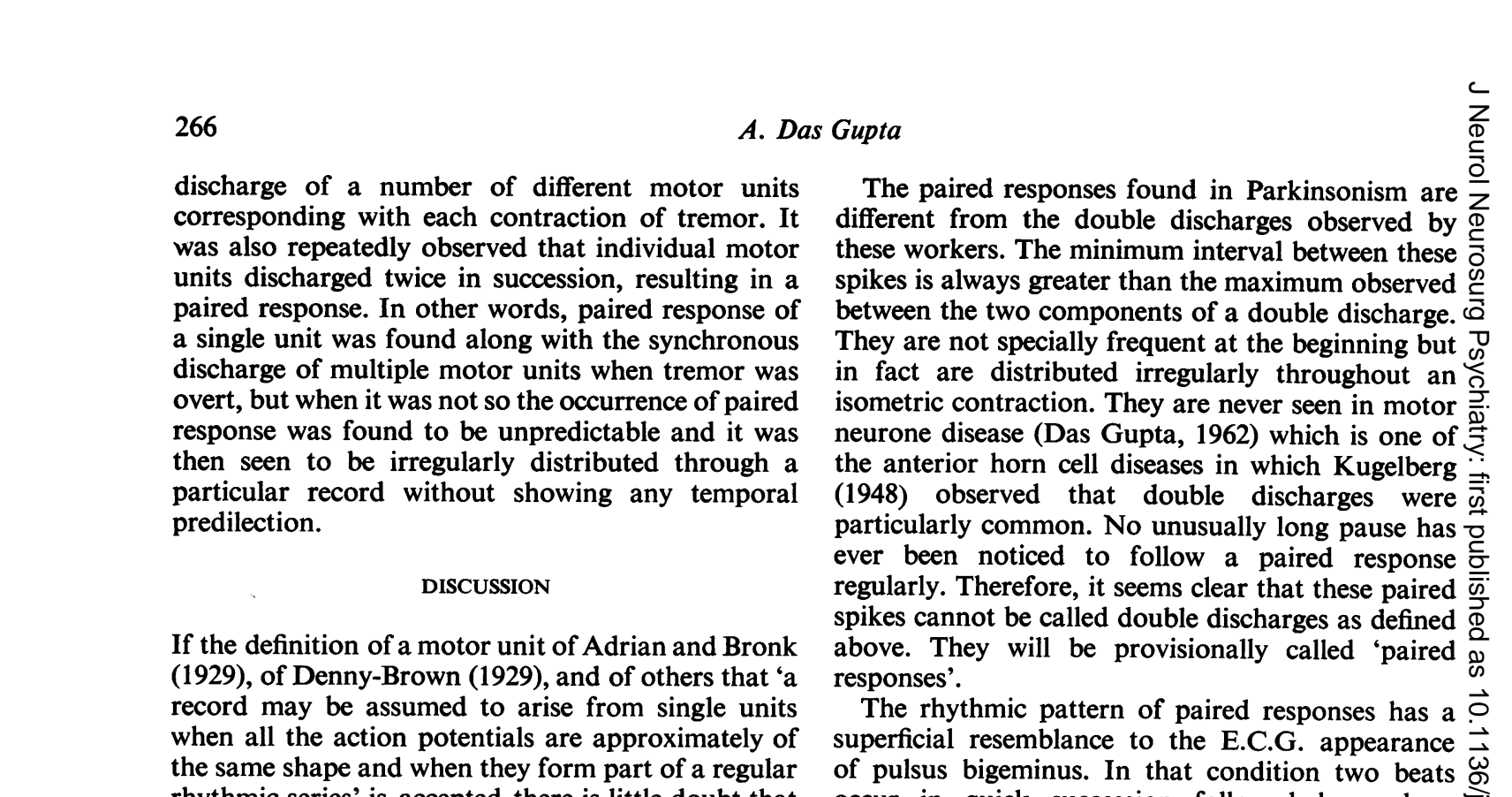

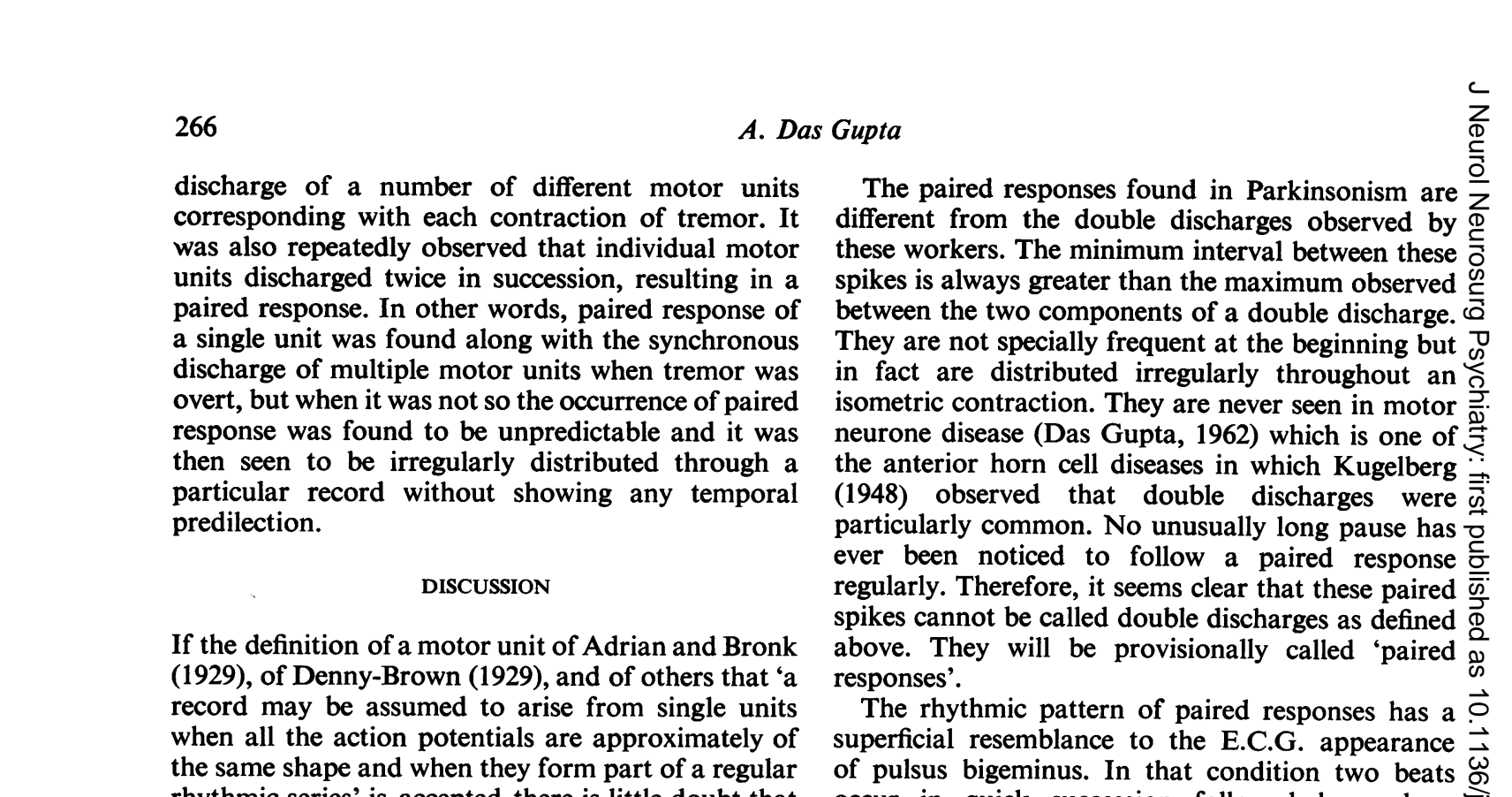

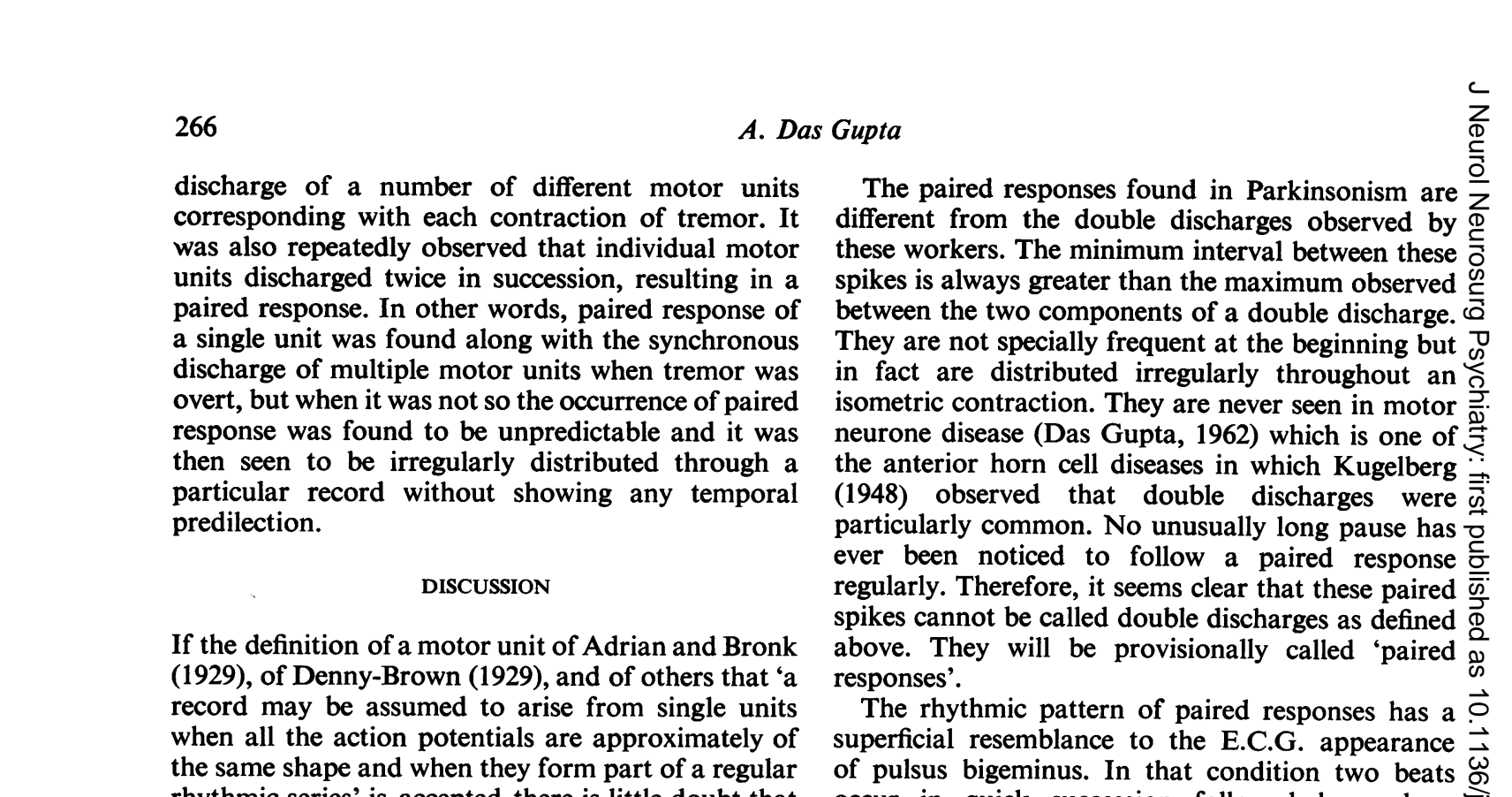

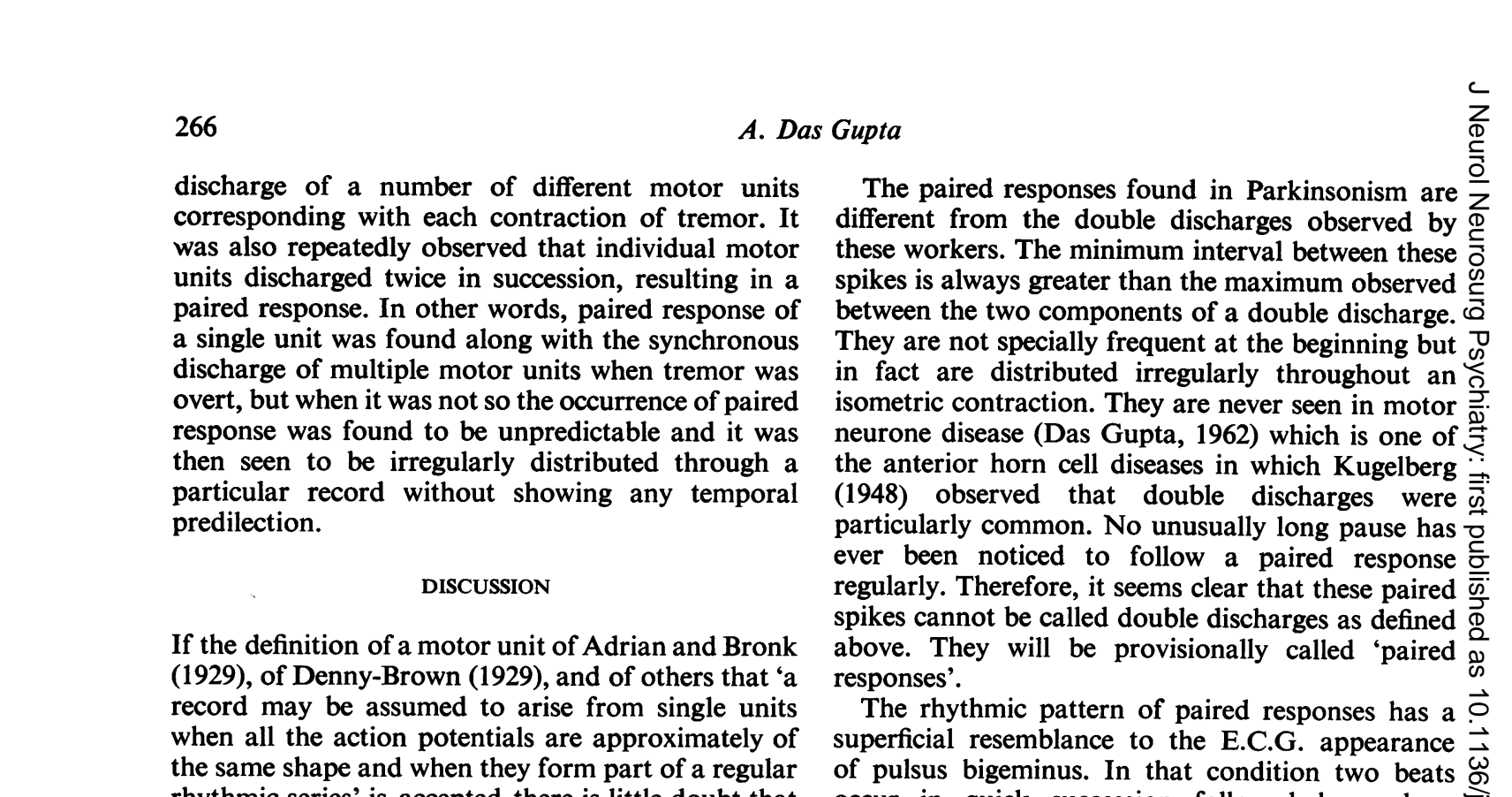

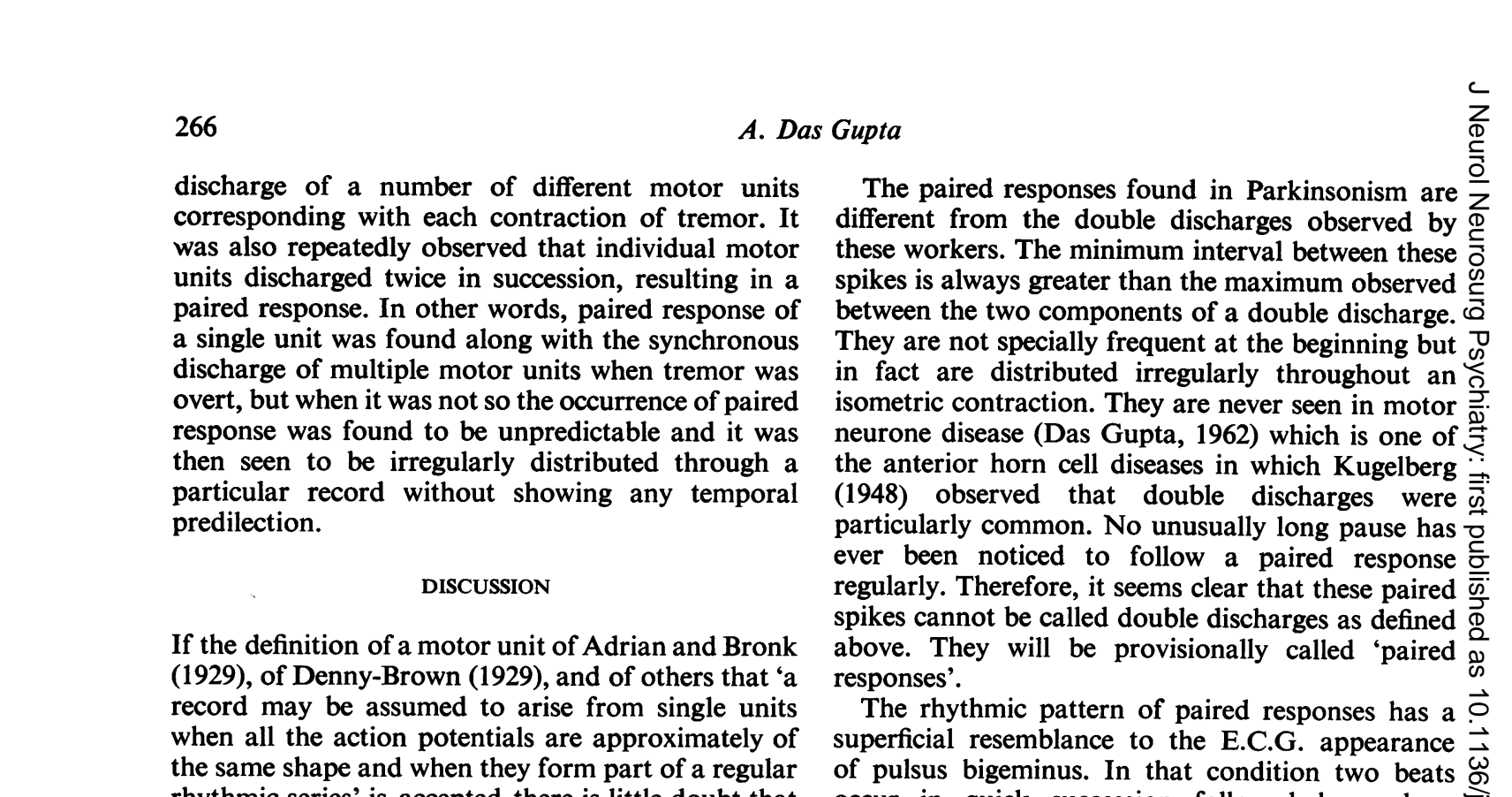
occur in quick succession followed by a long refractory period. The extrasystole which forms the second component of the coupled beat arises spontaneously as a result of the presence of $\$ \dot{\omega}$ 'supernormal phase' in the recovery cycle following in the first beat. In a variety of tissues, e.g., axons or sympathetic ganglia, myoneural junction, a singl subliminal stimulus may lower a threshold so muce्e that a second stimulus, itself normally subliminab may, after producing a 'temporal summation' wit the preceding one, reach a threshold intensity and $\vec{\bullet}$ thus produce an impulse (Hoff and Grant, 1944主 The paired response in Parkinsonism might at first sight suggest the presence of a supernormal phase following an original motor neurone discharge which can sometimes be raised above firing threshold in the presence of constant bombardment by afferent impulses, acting as a 'detonator' stimulus for the second discharge of the paired response. This theory is untenable because of the time factors involved. The supernormal phase following a motor neurone discharge varies from 3.0 to $15.0 \mathrm{msec}$. (Hoff and Grant, 1944). This interval is too short to explain the observed latency of 30 to $50 \mathrm{msec}$. between the two components of a paired response. Moreover, the duration of the recovery period following the second discharge of a pair is also significant. The subnormal period following repetitive firing of an excitable tissue tends to summate and this is the reason why there is always a long refractory period after pulsus bigeminus. The long period of electrical silence after a double discharge described by Denslow (1948), where the pairs were grouped within the time necessary to consider supernormality and summed subnormality in explanation, suggests that the double discharge is a true analogy with

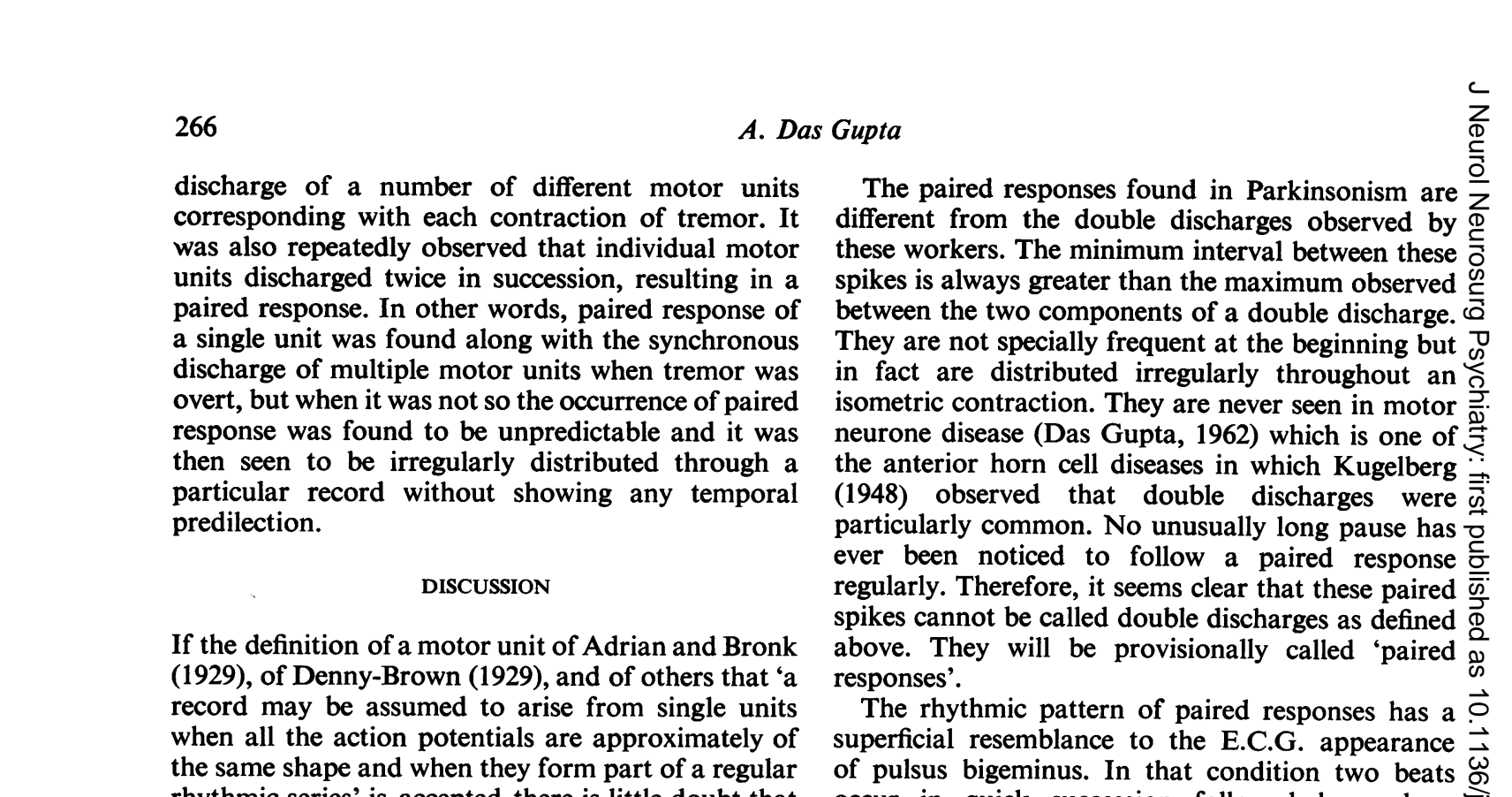

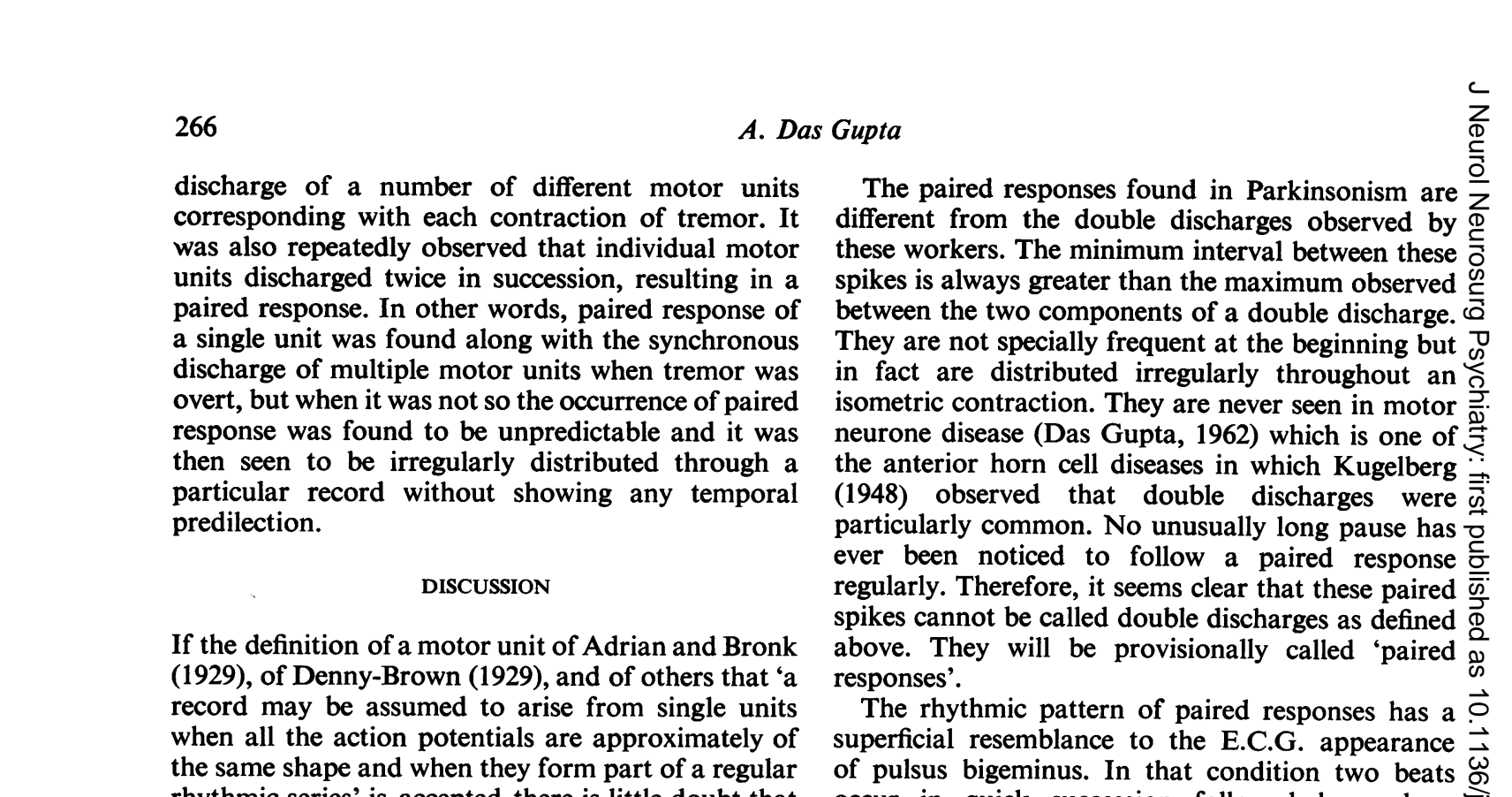

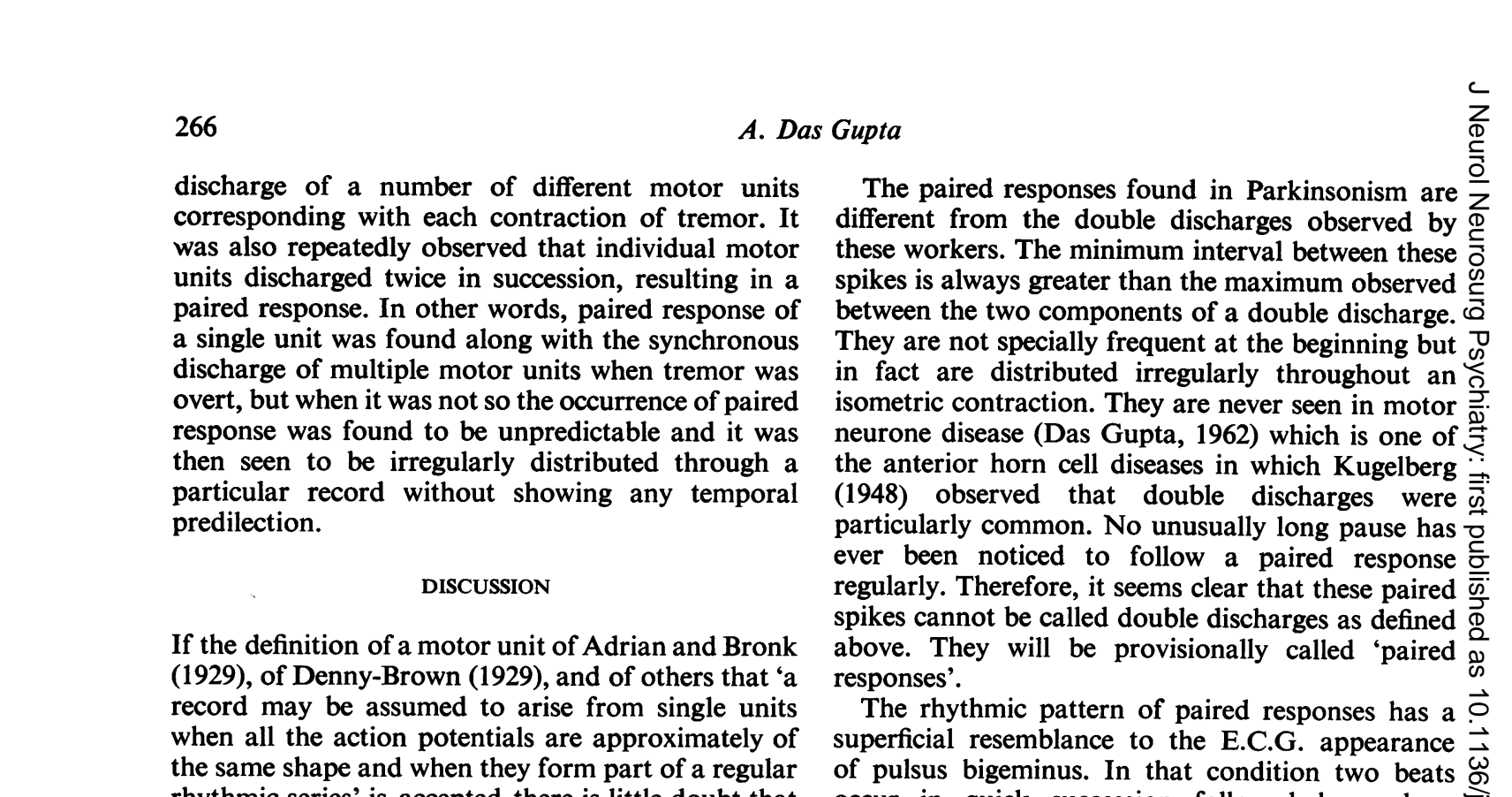

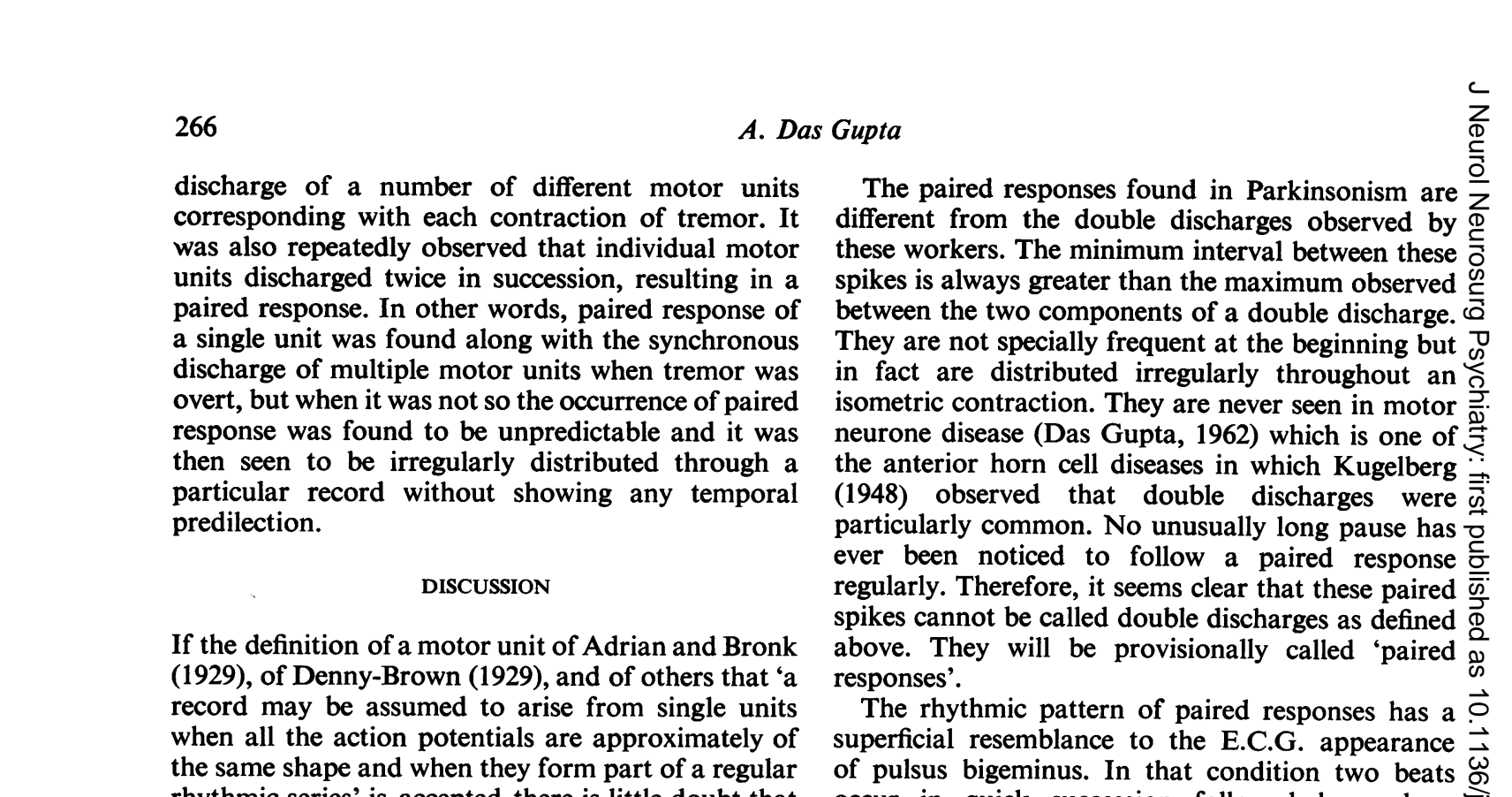

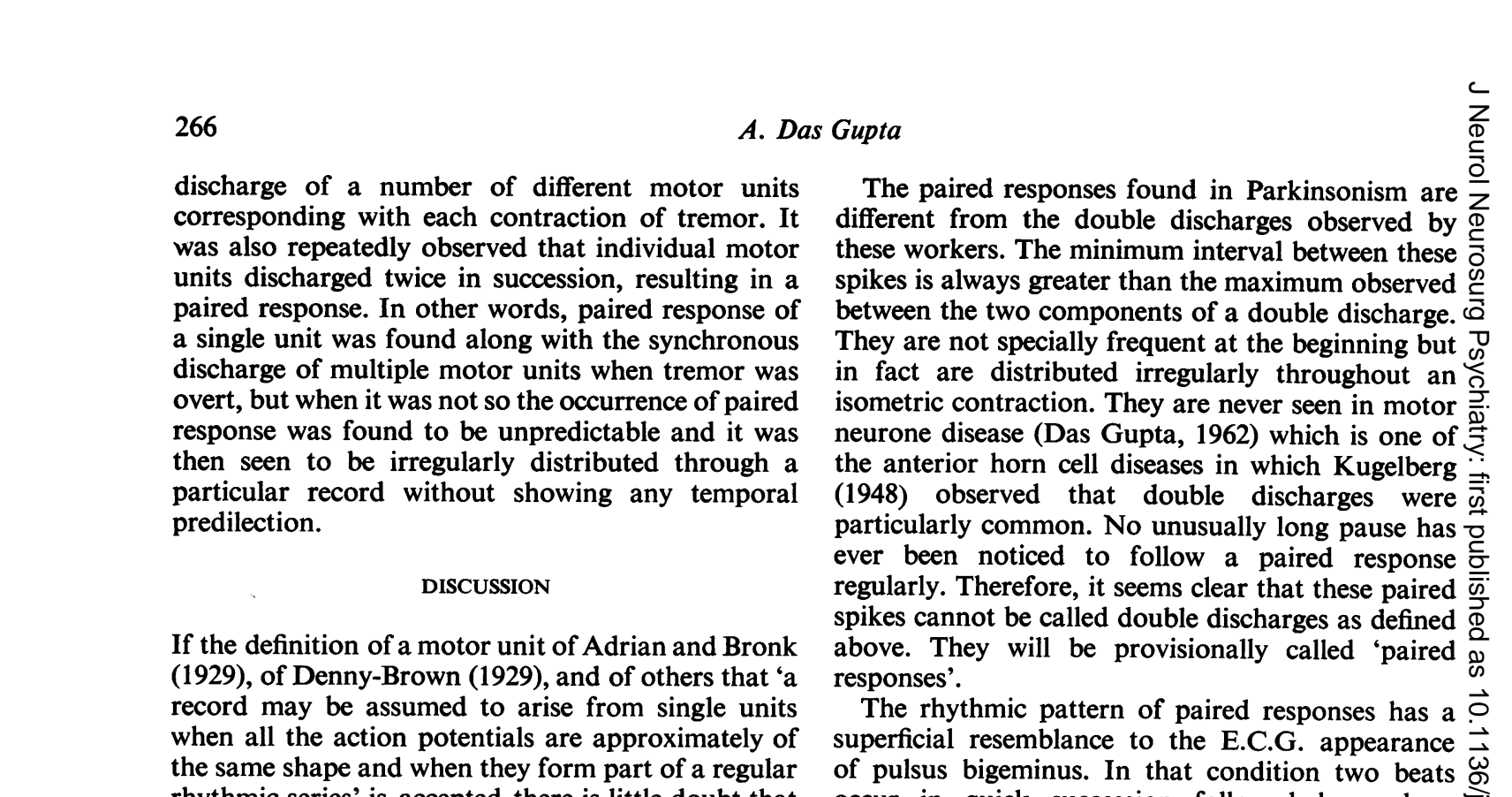

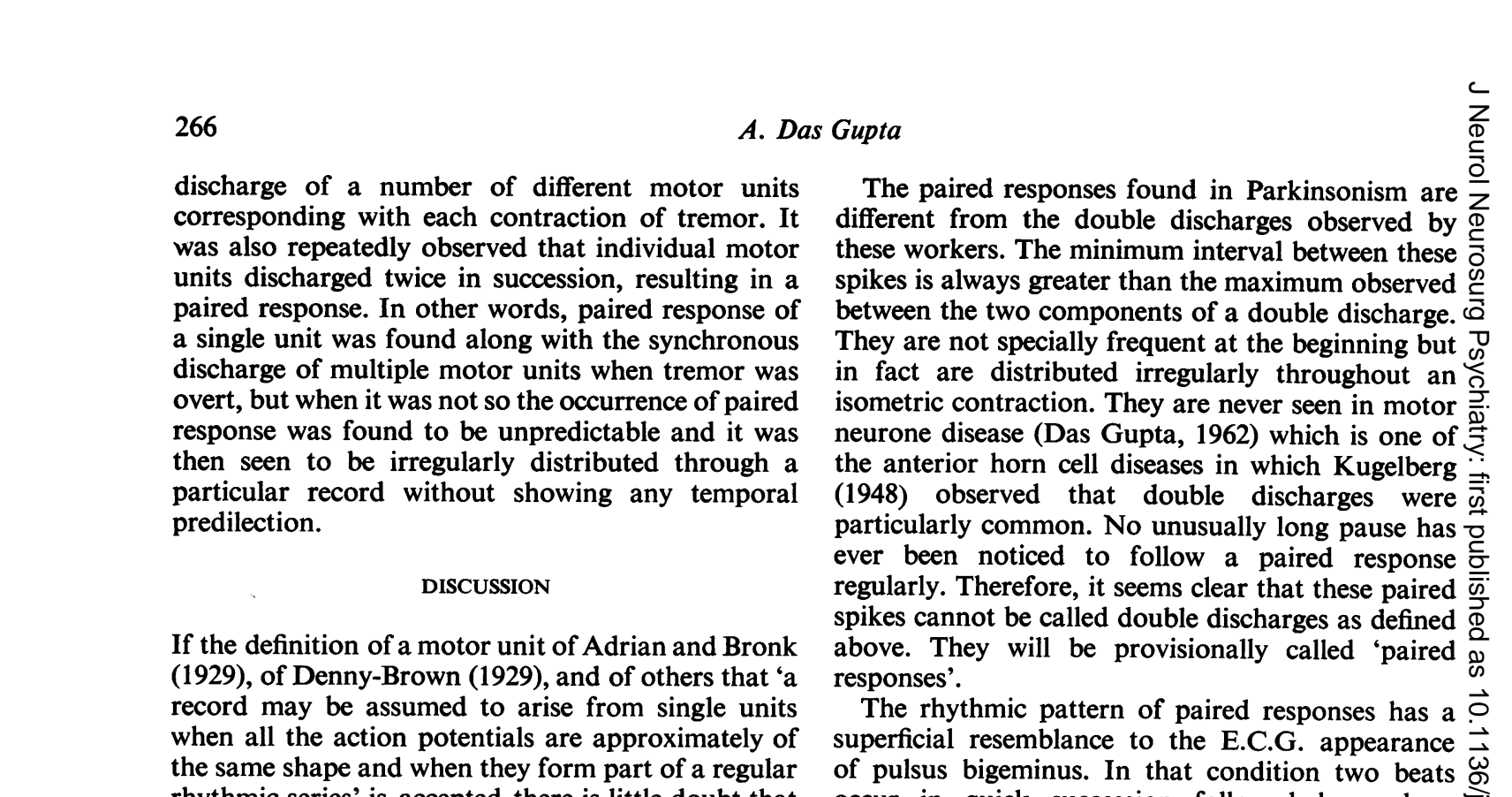

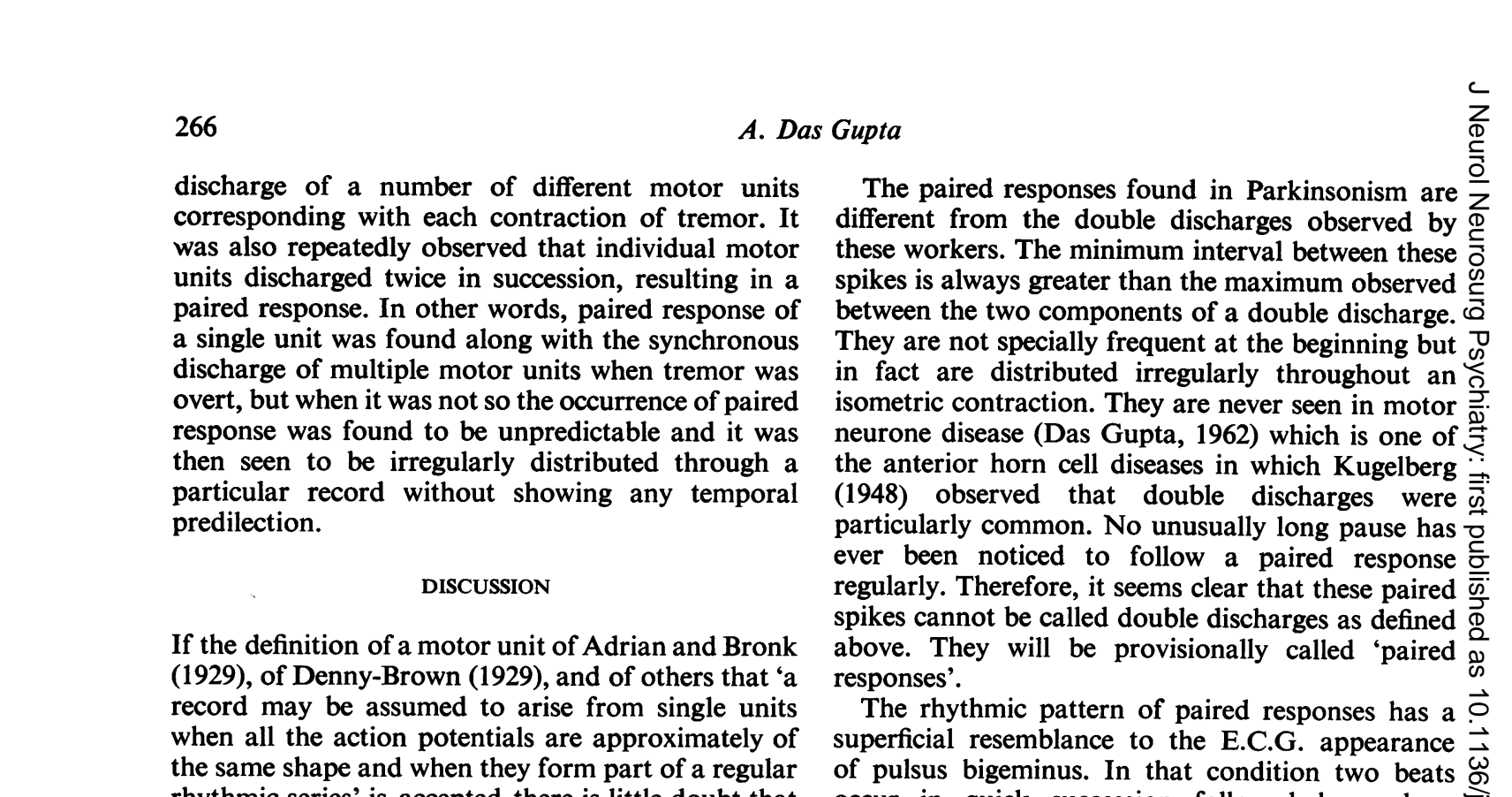

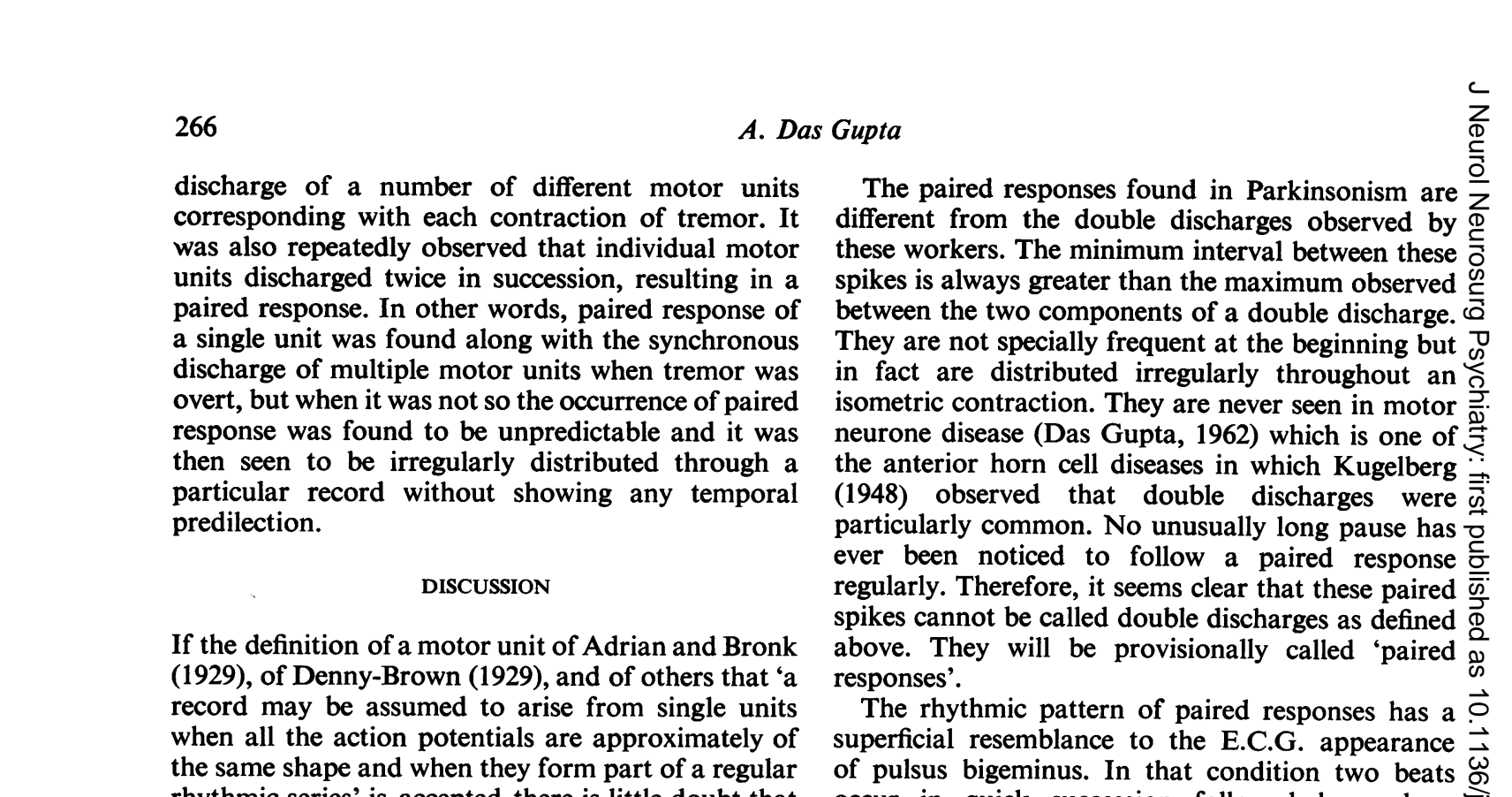

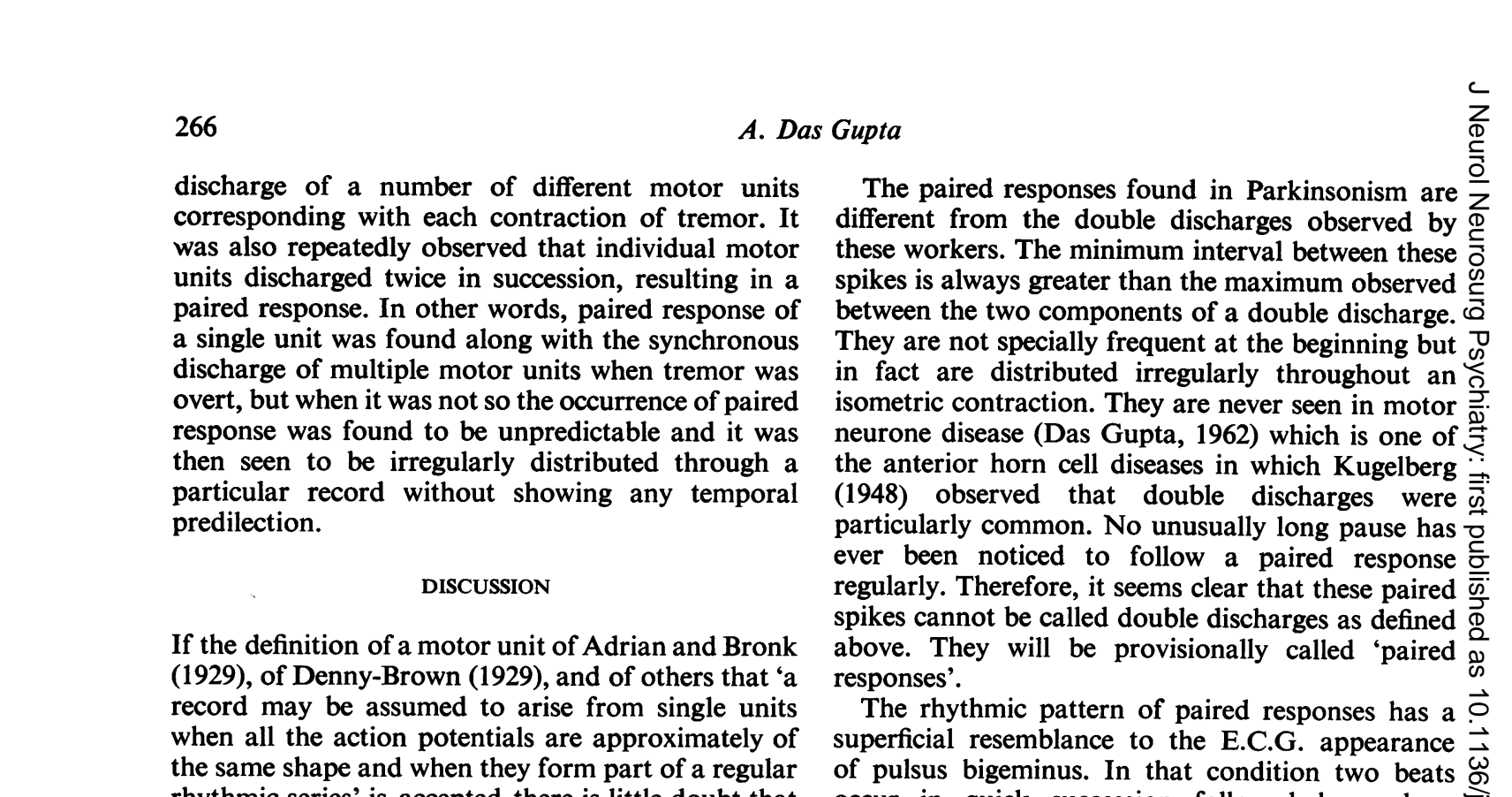

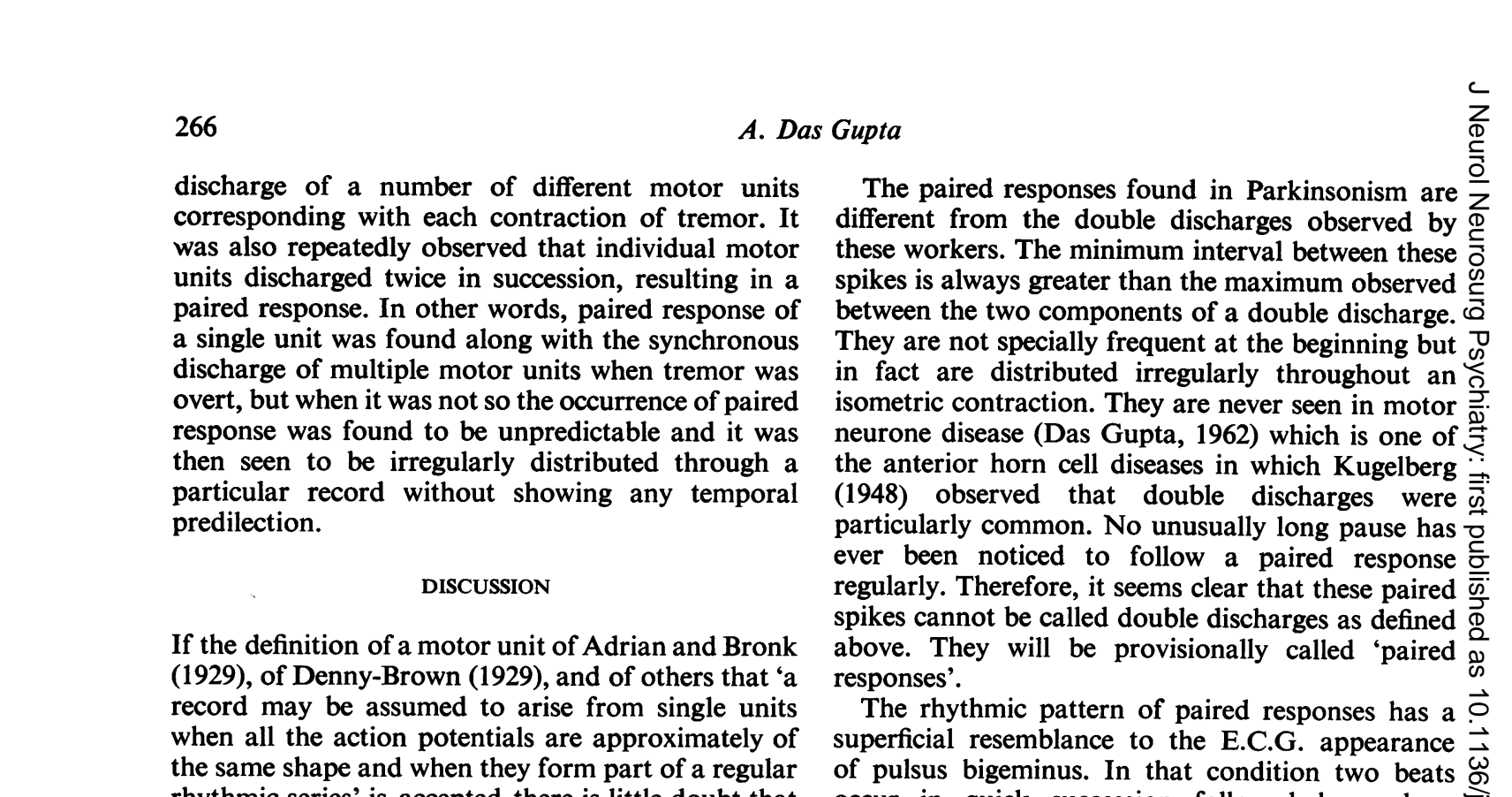

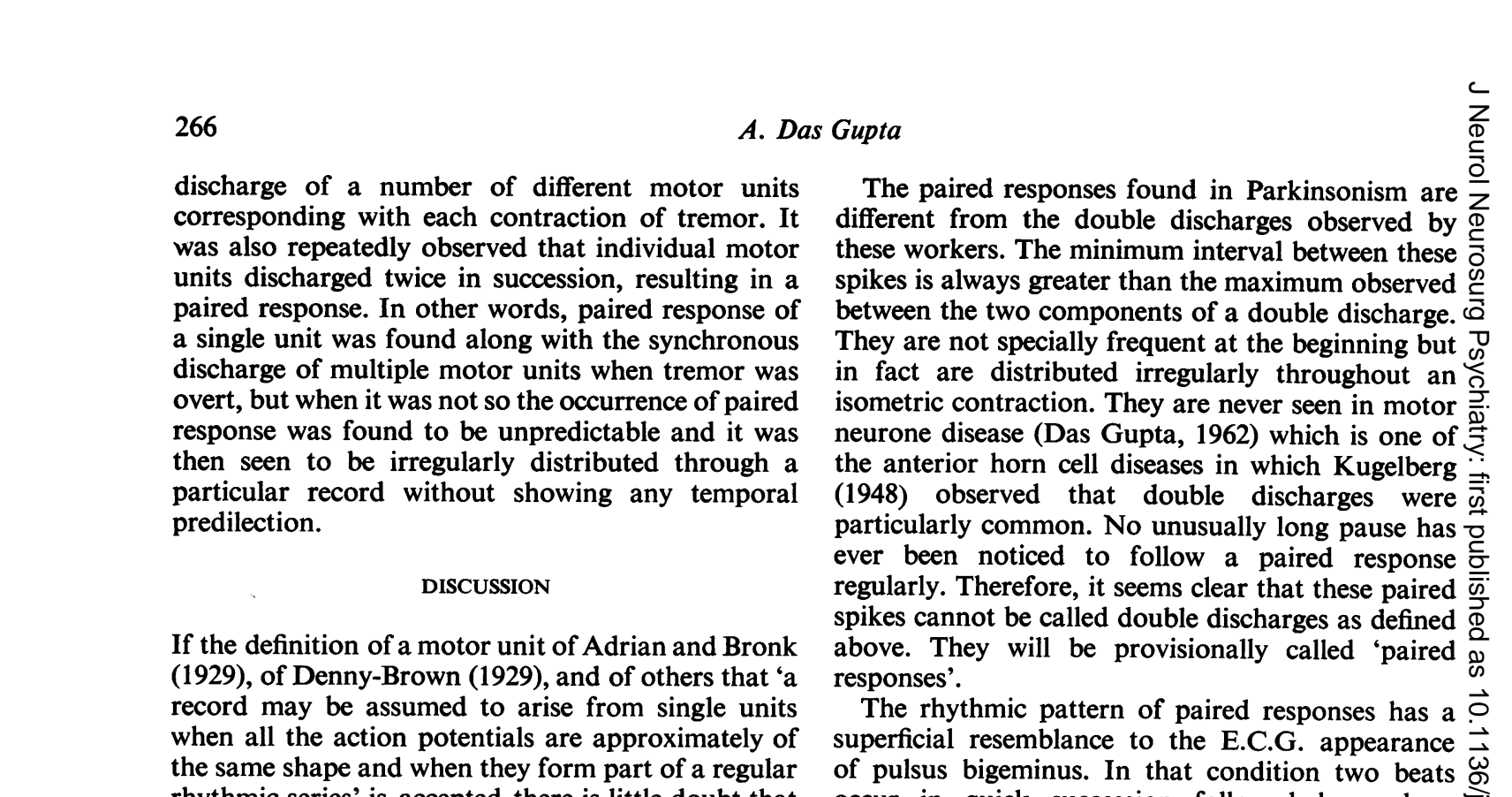

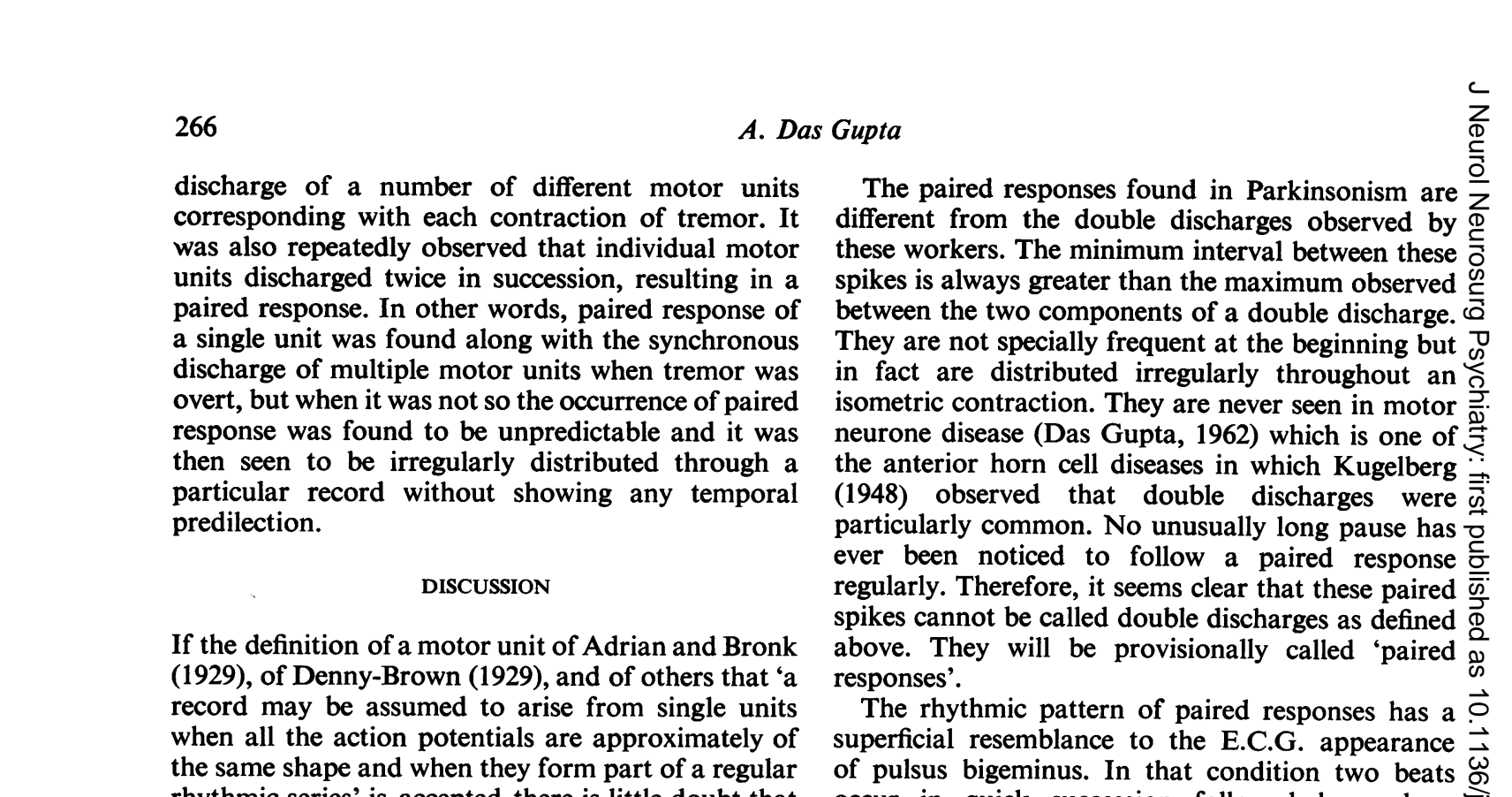

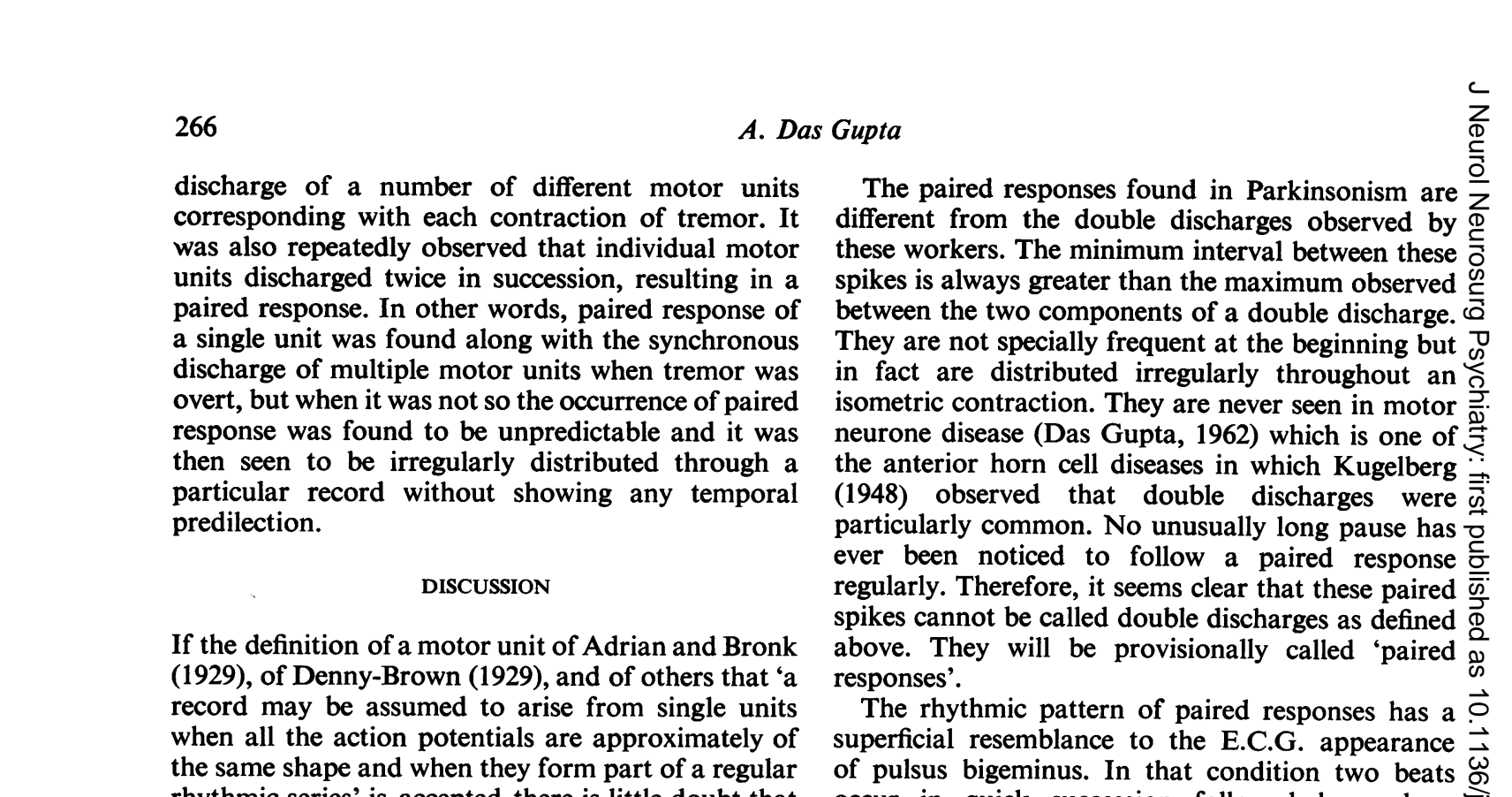

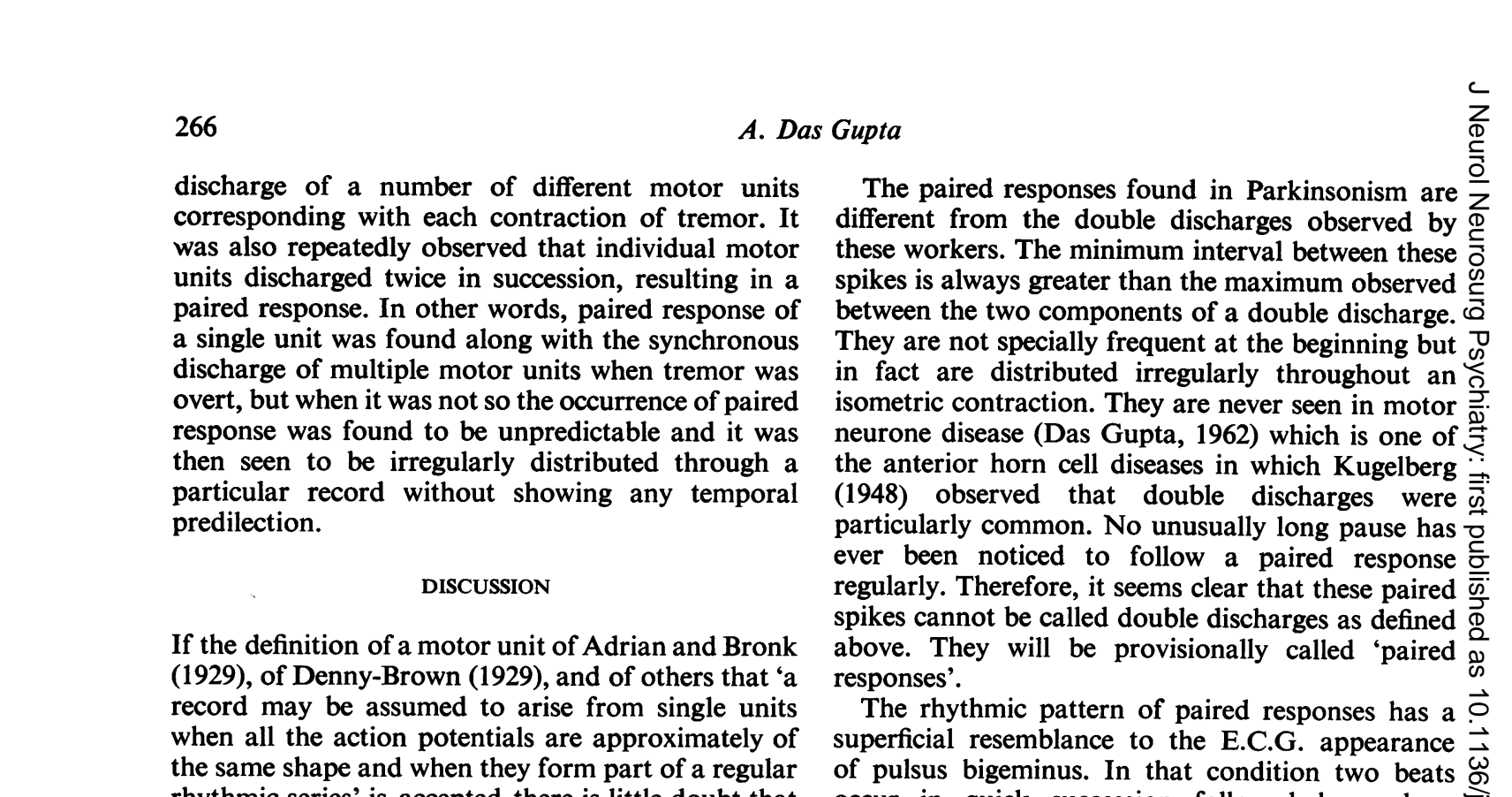

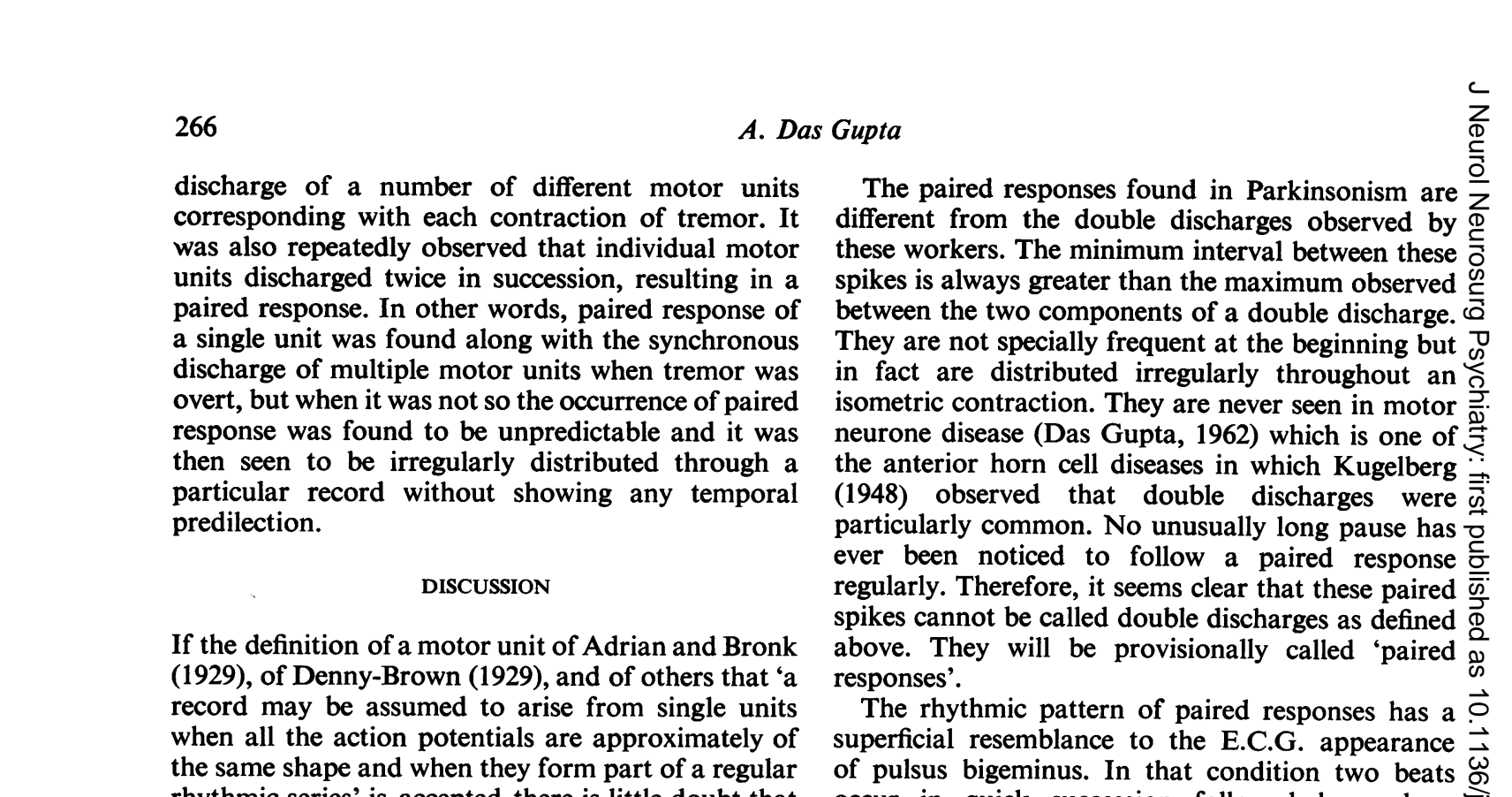

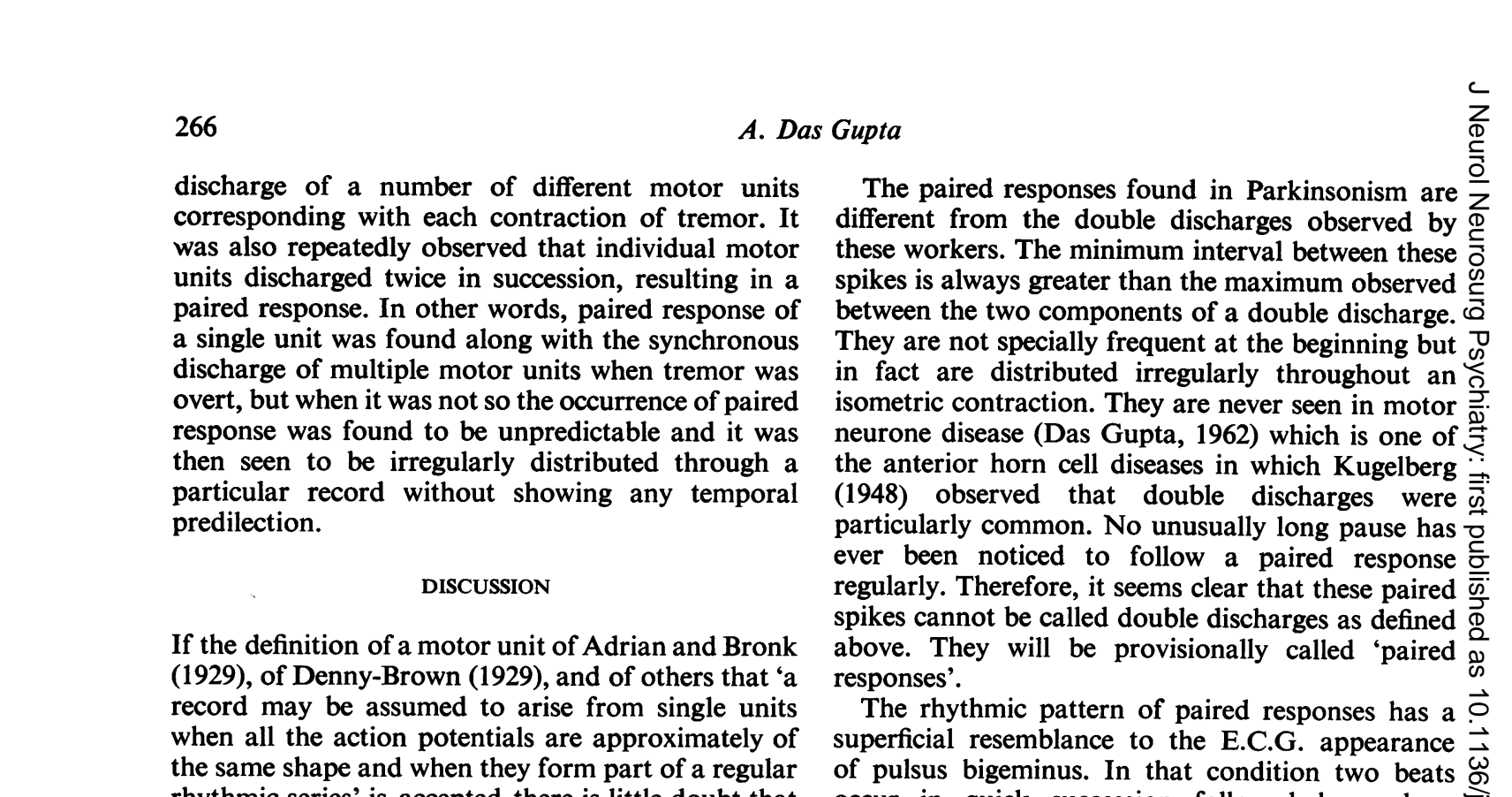

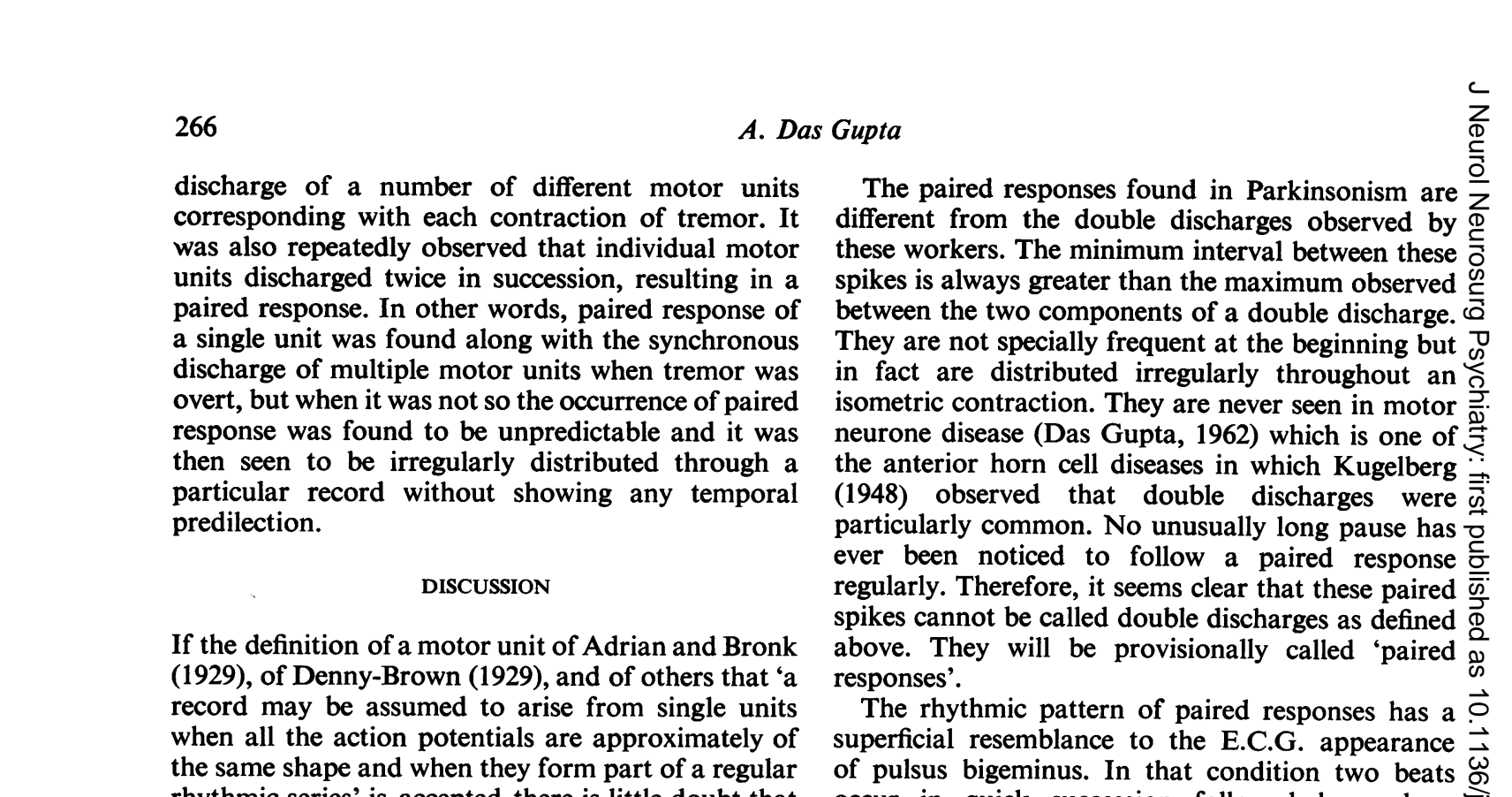

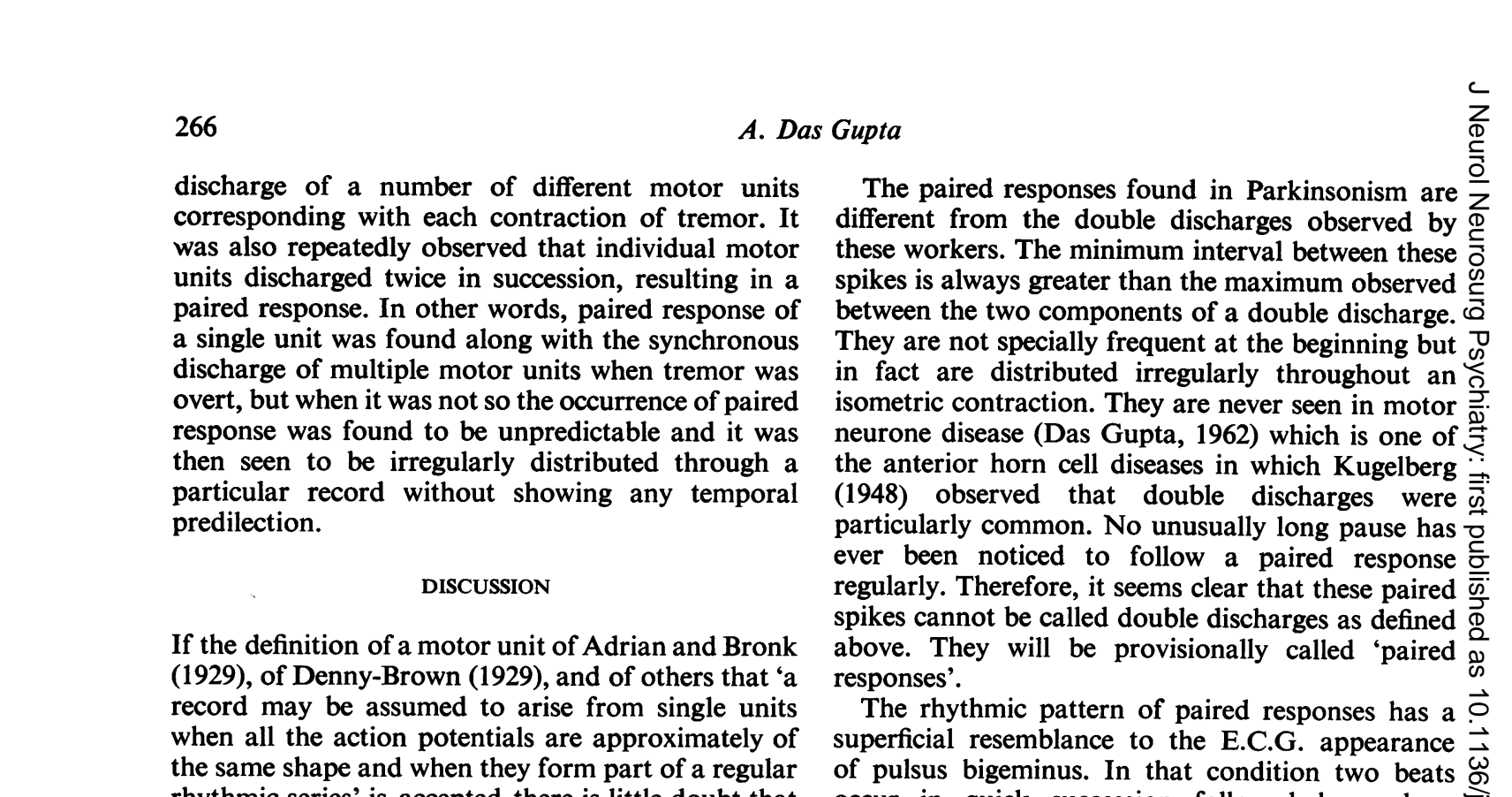

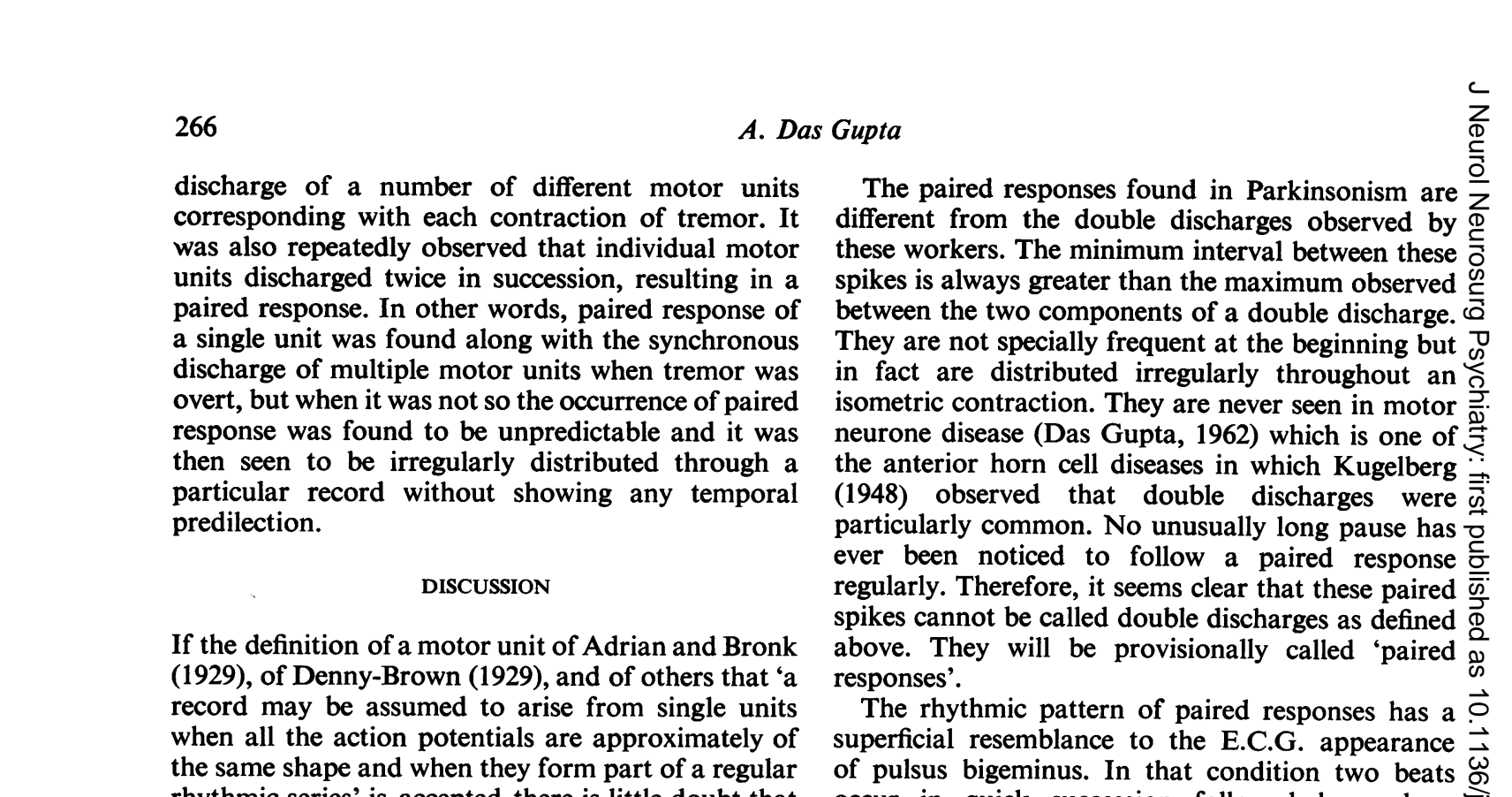

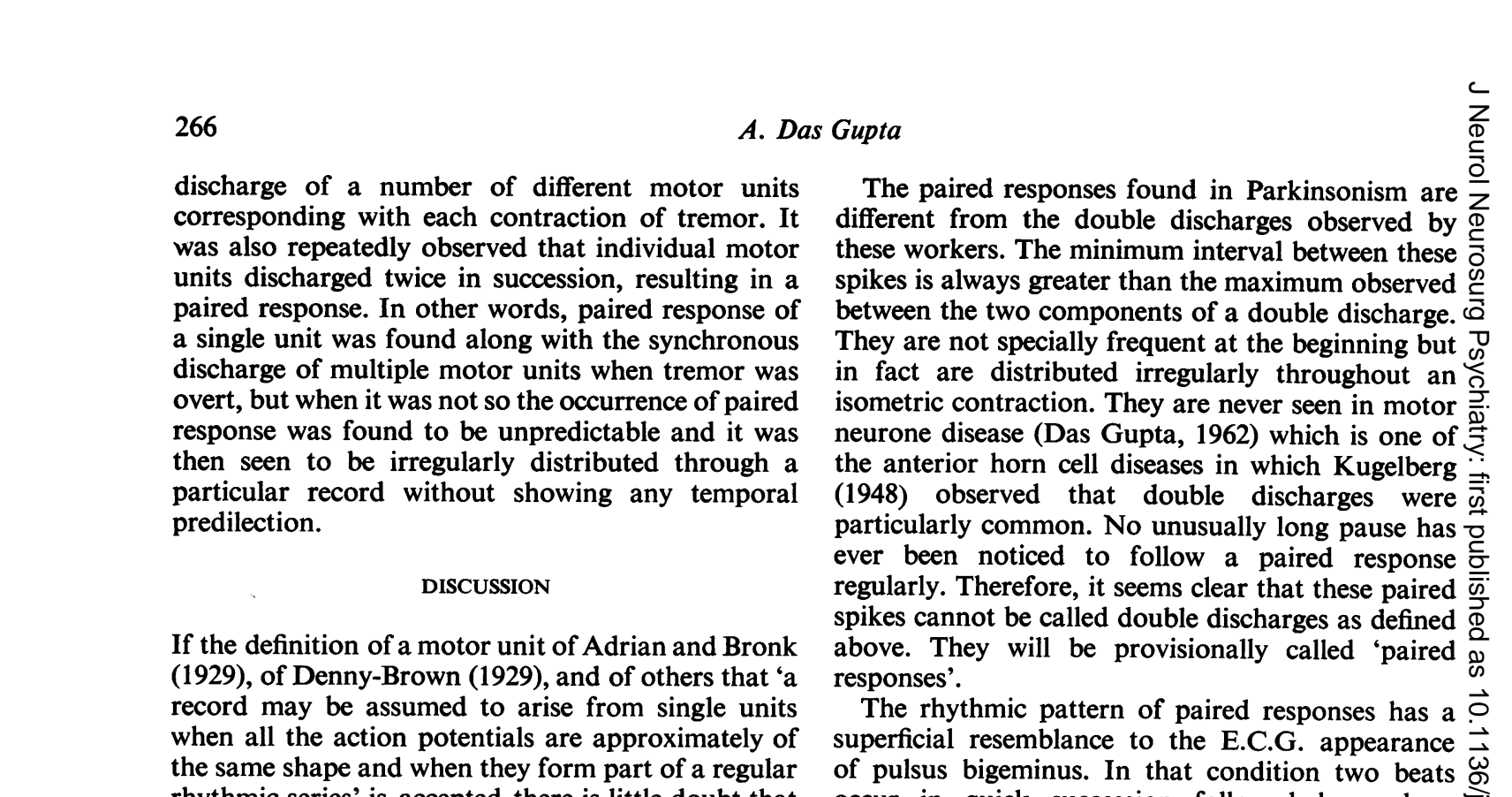


pulsus bigeminus. The temporal relations of the paired response are quite different. No compensatory pause has been noted to follow a paired response in this work, though I have been alert to the possibility of its occurrence. The wide gap between the discharges forming the pair and the absence of a compensatory pause make it most unlikely that the paired response is due to an abnormal excitability cycle of the motor neurone.

The question of whether Parkinsonian tremor is a spontaneous rhythm of central origin or a chain of reflex events is not merely of great theoretical interest, as its proper solution would have repercussions on both surgical and medical treatment. Jung (1941) has pointed out that the rhythmic trains of impulses of tremor cannot originate in the brain itself, and Schwab and Cobb (1939) failed to find any correlation between cortical electrical activity and the rate of Parkinsonian tremor. Jung (1941) favoured the opinion that the internuncial neurones of the spinal cord should be held responsible for it. This is reminiscent of Forbes's (1929) 'reverberating circuits', i.e., circuits of excitation which persist for considerable periods. Forbes (1929) and Lorente de Nó (1939) assumed the existence of such circuits and Delisle Burns (1958) actually suggested that the internuncial neurones are the site of origin of the rhythmical discharges. But the experiments of Lippold, Redfearn, and Vučo (1958) on rhythmic stretching of muscle in a decerebrate animal rule out a central rhythmical activity. In fact, though Delisle Burns (1958) supported the theory of 'reverberating circuits', he emphasized the dependence of excitation circulating in this circuit on external impulses. Any chain of interconnected neurones, such as the internuncial system of the cord, is potentially capable of simple oscillation if it is excited and maintained by impulses from outside the system.

It is well known that tremor in Parkinsonism appears after a period of quiescence and it then tends to build up progressively as if each tremor contraction were reinforcing the succeeding one. Conversely, patients are often able to reduce or abolish the tremor altogether by immobilizing the affected limb or by active voluntary contraction of it. Therefore, it seems that whatever may be the initiating cause, the stretch reflex impulses set off by each tremor burst help to maintain it (Bishop, Clare, and Price, 1948). The importance of this afferent inflow is further suggested by the effect on tremor of extensive posterior root section of a rigid limb as was done by Pollock and Davis (1930) who observed that 'although the tremor was not abolished, it was changed in amplitude, rhythm, and rate'.
It can be argued that the motor neurone pool would have a tendency to fire synchronously if some excitatory or inhibitory system rhythmically invades the supposed 'reverberating circuit' (Lippold et al., 1957). Hufschmidt (1959) suggested that the inhibitory impulses from the Golgi tendon organs are very much increased in Parkinsonism. According to this author, spinal motor neurones in this condition must be overreacting to those inhibitory impulses which might spread rhythmically along the circuit. 'The tremor', he writes, 'thus originates as a chain of heightened inhibition reflexes, and hence an additional heightening of tension or decrease of tension ... can predictably influence the tremor according to the point of application to the tremor cycle'. Granit, Pascoe, and Steg (1957) and Granit and Rutledge (1960) have also shown that 'doubling' of motor units can be produced by antidromic stimulation of a motor neurone during tonic firing. They noted that if the excitatory drive was sufficient antidromic inhibition was regularly succeeded by a brief phase of rebound excitation, definitely related to the preceding inhibition. They concluded that 'when reflex drive increases, a transition from pure inhibition to inhibition rebound can serve no other purpose than maintenance of the slow rhythm of discharge with double spikes instead of single spikes'. This hypothesis can very well explain the genesis of double discharges, but as discussed before, the rebound excitation succeeding peripheral inhibition is unlikely to last as long as 30 to $60 \mathrm{msec}$. (Hoff and Grant, 1944), and hence cannot produce a paired response.

The argument of Hufschmidt (1959) likewise may well explain the synchronization of motor units, but it is difficult to comprehend how it can give rise to a paired response of the same unit. This must be the manifestation of repetitive discharge of the motor neurone, due to some local cause (which has not been proved) or successive facilitatory stimuli must reach the motor neurone from some source, spinal or supraspinal.

A long maintained excitatory state would lead to repetitive firing of a motor neurone with a repetition period determined mainly by Renshaw inhibition. The period of 30 to $60 \mathrm{msec}$. between spikes of a paired response would be compatible with this (Renshaw, 1941 and 1946). It is suggested that the paired response is due to the interplay of a maintained excitatory state with a negative feedback of Renshaw type of the responding neurone. The crux of the problem remains the source of the maintained excitatory state. According to contemporary thinking this implies sustained activity of spinal interneurones. Conventional views on Parkinsonism would attribute this to tonic 'excitation' from brain-stem facilitatory 
centres. Personal observations on Parkinsonian patients (Das Gupta, 1962) also suggest the presence of some supraspinal inhibitory influence or tonic inhibition of peripheral origin (Hufschmidt, 1959). Neither mechanism is mutually exclusive, and indeed both may be necessary to resolve a paradox which the paired response has shown. It has not been a purpose of this paper to discuss the mechanism of tremor in Parkinsonism but it may be pointed out that an interplay of antagonistic tonic activities in spinal interneurones might lead to oscillation of the servo system and so cause a rhythmical tremor which would not require the presence of the same rhythmicity in a descending extrapyramidal outflow.

\section{SUMMARY}

A tendency for motor units of skeletal muscle to fire in paired responses during sustained isometric contraction is noted in patients with Parkinsonism.

Temporal relations exclude the possibility of paired responses due to the excitability cycle of the motor neurone but are compatible with a Renshaw type of inhibition modulating a tonic excitatory state.

Evidence of increased supraspinal and peripheral inhibition of motor neurone activity is referred to and it is suggested that an interplay of antagonistic tonic activities at spinal interneurone level might account for tremor in Parkinsonism.
This work was done during the tenure of a graduate research fellowship of the Faculty of Medicine, University of Edinburgh, and is a part of work submitted as a Ph.D. thesis. I am grateful to Dr. J. A. Simpson for help and advice.

\section{REFERENCES}

Adrian, E. D., and Bronk, D. W. (1929). J. Physiol., 67, 119.

Bishop, G. H., Clare, M. H., and Price, J. (1948). J. appl. Physiol., $1,123$.

Burns, B. Delisle (1958). The Mammalian Cerebral Cortex. Arnold, London.

Das Gupta, A. (1962). Ph.D. thesis, University of Edinburgh.

- , and Simpson, J. A. (1962). Electromyography, 2, 117.

Denny-Brown, D. E. (1929). Proc. roy. Soc. B, 104, 252

- (1929). Ibid., 104, 371.

Denslow, J. S. (1948). J. Neurophysiol., 11, 209.

Eccles, J. C., and Hoff, H. E. (1932). Proc. roy. Soc. B, 110, 483.

Forbes, A. (1929). In The Foundations of Experimental Psychology edited by C. Murchison. Clark University Press, Worcester, $\mathrm{C}$ Mass.

Gilson, A. S., and Mills, W. B. (1941). Amer. J. Physiol., 133, 658. Gordon, G., and Holbourn, A. H. S. (1949). J. Physiol. (Lond.), 110, 26.

Granit, R., Pascoe, J. E. and Steg. G. (1957). Ibid., 138, 381. and Rutledge, L. T. (1960). Ibid., 154, 288.

Hoff, H. E., and Grant, R. S. (1944). J. Neurophysiol., 7, 305. Hufschmidt, H.-J. (1959). Disch. Z. Nervenheilk., 178, 585.

Jung, R. (1941). Z. ges. Neurol. Psychiat., 173, 263.

Kugelberg, E. (1948). Arch. Neurol. Psychiat. (Chicago), 60, 153. (1948). Ibid., 60, 140.

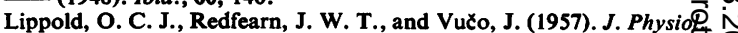
(Lond.), 137, 473.

,- - - (1958). Ibid., 144, 373.

Lorente de Nó, R. (1939). J. Neurophysiol., 2, 402.

Pollock, L. J., and Davis, L. (1930). Arch. Neurol. Psychiat. (Chicago 23, 303.

Renshaw, B. (1941). J. Neurophysiol., 4, 167.

(1946). Ibid., 3, 191.

Schwab, R. S., and Cobb, S. (1939). Ibid., 2, 36. 